\title{
Blown Arc Plasma Source for the Elaboration of Finely Structured Coatings
}

\author{
Vincent Rat ${ }^{*}$, Jean-François Coudert, Alain Denoirjean and Ghislain Montavon
}

SPCTS-CNRS UMR 6638, Faculty of Sciences, University of Limoges, 123 av. A. Thomas 87060 Limoges cedex, France

\begin{abstract}
New emerging technologies using blown arc plasma sources allow elaborating finely structured coatings which find many applications fields. Among them, Suspension Plasma Spraying consists in injecting within a dc plasma jet a liquid jet containing submicron solid particles which are plasma-sprayed to form coatings. This new technology has renewed the interest devoted to the understanding and the development of blown arc plasma sources. This paper focuses on a non-exhaustive description of standard (subsonic) de plasma torches involving blown arcs related to the Suspension Plasma Spraying (SPS). The emphasis is put on important features for SPS, i.e. on the influence of operating parameters on plasma properties, the understanding of the origin of electric arc instabilities and their influence on suspension injection, and at last, the coating characteristics.
\end{abstract}

Keywords: Blow arcs, dc plasma jet, electric arc instabilities, suspension plasma spraying.

\section{INTRODUCTION}

Finely structured coatings with intermediate thicknesses $(2-50 \mu \mathrm{m})$ and including nanomaterials are nowadays intensively studied because they find many application fields, e.g. fuel cells, catalytic membrane reactor, photocatalysis, wear resistance and thermal barrier coatings, among the principal ones. They are therefore synthesized for very specific purposes which lead to develop powerful elaboration processes to achieve the appropriate advanced functionalization.

Since about ten years, new thermal plasma based processes are under development to tackle these new challenges. Thermal plasmas involve high levels of energy densities $\left(>10^{9} \mathrm{~J} \cdot \mathrm{m}^{-3}\right)$ and therefore produce a highly reactive medium with strong quenching rates [1]. Consequently, they are particularly adapted to treat refractory materials or manage phase changes of liquid precursors and finally deposit ceramic coatings. Suspension Plasma Spraying (SPS) and Solution Precursor Plasma Spraying (SPPS) [2, 3] indeed permits to form finely structured coatings by injecting within a thermal plasma jet submicron solid particles or liquid precursors. The latter are then plasma-treated, i.e. liquid is atomized and vaporized, and solid particles are sprayed onto a substrate.

Thermal plasma jets can be generated by means of several different plasma torch technologies based on either radio-frequency inductively coupled discharges or electric arcs [4]. Among plasma torches of the latter group, direct current (dc) plasma torches with stick-type thermo-emissive cathodes (10-150 kW) operating at atmospheric pressure are probably the most basic ones and are widely used because of their ability to work with a wide range of operating

\footnotetext{
*Address correspondence to this author at the SPCTS-CNRS UMR 6638, Faculty of Sciences, University of Limoges, 123 av. A. Thomas 87060 Limoges cedex, France; E-mail: vincent.rat@unilim.fr
}

parameters and their easiness of installation. Plasma forming gases can be either axially injected within the torch or with an azimuthal velocity component and are heated up by Joule effect in the arc region. Due to plasma confinement within the anode-nozzle, the resulting plasma jet presents a strong axial convective velocity which stabilizes the arc and blows it downstream. This stabilization effect mainly operates on the cathode jet at the cathode tip and on the arc column, but the dynamics of the arc root at the anode wall depends on (im)balances of hydrodynamic and magnetic forces exerting on current lines. Moreover, strong arc current densities at the anode wall $\left(>10^{9} \mathrm{~A} . \mathrm{m}^{-2}\right)$ cause progressive electrode erosion which leads to reduce the energetic efficiency of these plasma torches. To limit these problems of erosion and arc instabilities, multi-electrode dc plasma torches were developed [5]. They are consisted of three stick-type hot cathodes to equally distribute the total arc current and a "neutrode" can be inserted upstream of the anode to stretch the arc column. The amplitude of arc fluctuations are then limited by the use of appropriate operating conditions (e.g., reduction of molecular gas content in plasma forming gases) and the increase of the mean arc voltage $(120 \mathrm{~V}$ against about $70 \mathrm{~V}$ in standard dc plasma torches). When reducing the ambient pressure (below $300 \mathrm{~Pa}$ ), dc plasma torches equipped with a convergent-divergent anode-nozzle generate supersonic plasma jets. On the one hand, when spraying solid particles, supersonic plasma jets permit to increase the impact particles velocities and therefore form dense coatings. On the other hand, a chemically reactive medium is generated due to the thermodynamic and chemical nonequilibrium state which favors the formation, for instance, of titanium nitride ceramic coatings [6].

Plasma torches with well-type cold cathodes $(100 \mathrm{~kW}$ $2 \mathrm{MW}$ ) generate thermal plasma jets which are in general used for waste treatment and for the synthesis of syn-gas [7]. A vortex injection of plasma forming gases and a magnetic field allows obtaining high mean arc voltage (>1000 V) and participating in electric arc motions [8-10]. 
At last, in water plasma torches, a steam thermal plasma jet allows reaching high temperatures (> $25000 \mathrm{~K}$ ) and velocities $\left(5000 \mathrm{~m} . \mathrm{s}^{-1}\right)$ at the nozzle exit due to strong arc constriction and are used for ceramic coatings and also for the production of syn-gas [11].

It is not the purpose of this paper to review all these dc plasma torches since they were described in details in previous review papers encompassing their applications [4, 12-14]. Moreover, recent papers concerning thermal plasma modelling were also written reviewing thermodynamic and transport properties, and also advanced numerical simulations in thermal plasmas [15-18]. Instead, this paper will focus on the description of standard (subsonic) dc plasma torches involving blown arcs related to the Suspension Plasma Spraying process.

After the presentation of dc plasma torch features in the next section, we will show in section 2.2 how a macroscopic and energetic approach of a dc plasma torch, thanks to a simplified model, allows predicting the main averaged plasma jet properties (electrode thermal losses, mean electric field, plasma velocity, pressure). Since these properties are shown to be dependent upon basic mean experimental measurements (arc voltage, electrodes thermal losses, mean pressure), it can be then deduced how are affected the mean plasma jet properties as function of operating parameters.

This approach is very useful to adapt plasma jet properties to solid or liquid precursors to be plasma treated, however, the reduction in size of such precursors to form finely structured coatings make them very sensitive to spatial non-uniformities and temporal instabilities of plasma properties.

Consequently, in section 2.3, a complementary approach presents the origin of arc instabilities focusing on a very recent description of such a dc plasma torch in terms of Helmholtz resonator.

At last, section 3 will present main features of typical SPS coatings obtained by the use of blown arc plasma torch, in particular a very peculiar dual microstructure.

\section{BLOWN ARC PLASMA SOURCE}

\subsection{De plasma Torch}

A dc commercial (Sulzer Metco F4) plasma torch is used and the process, depicted in Fig. (1), is power supplied with a current regulated source and the gas feeding rate is controlled with a mass flow meter. The current regulated electric power supply (SNMI P130, France) delivers a maximum current intensity of 1000 A corresponding to a maximum electric power of $100 \mathrm{~kW}$. The arc current fluctuations present a root mean square (RMS) value less than $1 \%$ of the mean value so that the current should be considered as constant in the following. High voltage sparks are used to ignite the arc through a choke circuit used to isolate the power supply from the ignition source. The input parameters are the arc current, I, the gas mass flow rate, $\dot{m}_{g}$ and the gas composition. The dependent, or output, parameters are the arc voltage, $\mathrm{V}$, and the heat losses to the electrodes, $P_{t h}$. This dc commercial plasma torch is presented in this paper because it is widely used not only in research laboratories but also in industrial applications. However, the discussion below is not restricted to this plasma torch and can be extended to other plasma torch geometries, in particular presenting a similar time dependence of arc voltage to that described in section 2.3.1.

Plasma forming gases are injected in the rear part of torch through an injection ring drilled at $8 \mathrm{~mm}$ from the torch axis by 16 holes, $1 \mathrm{~mm}$ in diameter, tilted at $45^{\circ}$. The arc is ignited between the cathode tip and the cylindrical anode. The electrodes are water-cooled and temperature measurements between the input and output pressurized water allows obtaining the thermal power lost in the cooling circuit.

The stick-type cathode is made of thoriated tungsten (1$2 \mathrm{wt} \% \mathrm{ThO}_{2}$ ). The main mechanism of electron emission at the cathode tip is the thermoionic effect according to the Richardson-Dushmann law [4]. Cathode temperature and electron emission area depends on cathode design, the

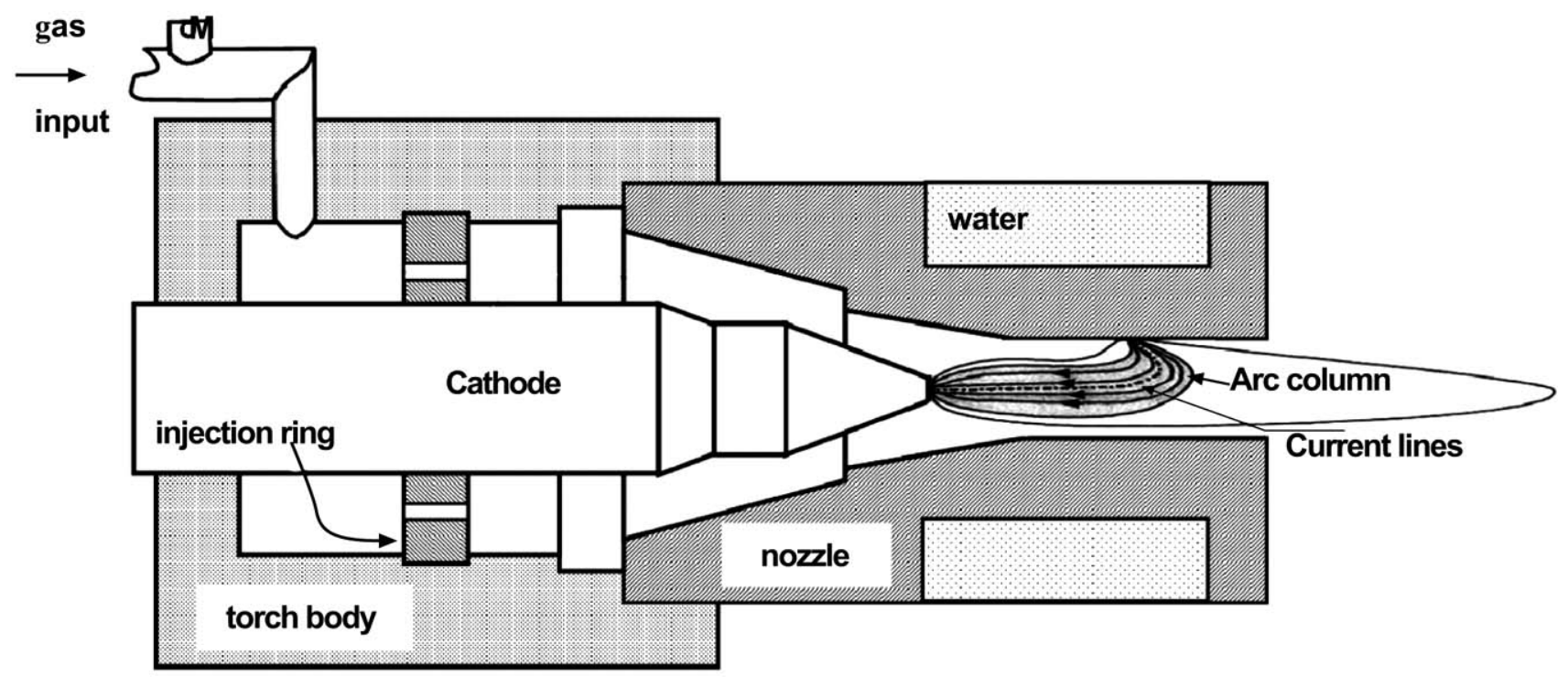

Fig. (1). Simplified scheme of a dc plasma torch operating with cathode rod at atmospheric pressure (Sulzer Metco F4 type). 
efficiency of its water-cooling and gas injection around it [19].

Curvatures of current lines at the cathode tip provoke self-induced magnetic striction of current lines and generate a flow velocity axial component (cathodic jet) by Maecker effect [20]. The use of dopant within cathode in principle lowers the electron work function favouring their emission but it is also evaporated due high temperatures at the cathode tip. Further downstream the cathode tip, the plasma jet expanses within the nozzle channel which the internal diameter varies between 6 and $8 \mathrm{~mm}$. The anode-nozzle is made of copper with a tungsten insert and receives convective and electrical heat fluxes respectively from the arc column and the arc root.

\subsection{Macroscopic Description of de Plasma Torch}

\subsubsection{Thermodynamic and Transport Properties of Thermal Plasmas}

Thermal plasmas are usually described as complete local thermodynamical equilibrium (LTE) plasmas, where chemical and thermal equilibria are reached (optically thin and collision dominated). In blown arc generated thermal plasmas at atmospheric pressure, these conditions are fulfilled (except regions near electrodes and in the fringes), and the plasma is considered as a perfect gas where the specific enthalpy can be evaluated [21]. The gas used in plasma torches devoted to thermal spraying must be chemically neutral to reduce the erosion of electrodes which are generally made of tungsten. Argon is present most of time in the gas mixture because of its rather low ionization potential $(14.5 \mathrm{eV})$ and also because of its atomic weight which is essential for the momentum transfer plasma-solid particles. Hydrogen is added to increase the specific enthalpy of the plasma and to improve heat transfers. Helium is sometimes used in addition to argon because it contributes to increase both the isentropic coefficient and the dynamic viscosity of the plasma gas, which improve the momentum of solid particles. Fig. (2) shows the dependence on temperature of calculated specific enthalpy for various plasma gases (Ar, Ar- $\mathrm{H}_{2}$ (75-25\%vol), N 2 , Ar-He (25$75 \%$ vol), Ar- $\mathrm{H}_{2}-\mathrm{He}$ (40-10-50\%vol)), currently used in plasma spraying. The changes of slope in enthalpy curves are mainly due to dissociation and ionization processes.

It is interesting to note that variations of enthalpy are much more pronounced than temperature when chemical reactions occur. Consequently, the description of transport properties in terms of enthalpy instead of temperature is of interest as shown below in the simplified model of a blown arc plasma.

For $\mathrm{Ar}, \mathrm{Ar}-\mathrm{H}_{2}$ or $\mathrm{N}_{2}$, the linear plot of electrical conductivity versus temperature shows the same tendency, that is an almost zero value at low temperature and a linear increase after a threshold value is reached. The intercept of the linear evolution with the temperature axis allows defining a critical temperature, $\mathrm{T}_{\mathrm{c}}$, i.e. about $7500 \mathrm{~K}$ for the above mentioned gases [22]. In this stepwise approximation, the electrical conductivity should be zero under $T_{c}$ and proportional to $\left(\mathrm{T}-\mathrm{T}_{\mathrm{c}}\right.$ ) above $\mathrm{T}_{\mathrm{c}}$. A conduction threshold is also observed if temperature is replaced by specific enthalpy as independent parameter, setting $h_{c}=h\left(T_{c}\right)$.
Fig. (3) shows the dependence of electrical conductivity of the preceding plasma gases on specific enthalpy. A conduction threshold is observed because enthalpy strongly increases when ionization takes place.

At moderate specific enthalpy, the electrical conductivity can be simply fitted by using a basic square root function as follows:

$\sigma(h)=a_{\sigma}\left(h-h_{c}\right)^{0.5}$ for $h \geq h_{c}=h(T c)$

This relationship allows defining a critical specific enthalpy $h_{c}$ which represents the electrical conduction threshold. This critical enthalpy will be used in the double layer model (section 2.2.2) where enthalpy profiles are determined in the arc column and in the cold layer situated between the anode electrode wall and the arc column. The onset of electrical conduction will be represented by $h_{c}$.

This approximation is valid from $h_{c}$ up to a specific enthalpy corresponding to temperature levels consistent with those found in electric arc based processes (except close to electrodes), i.e. up to $14000 \mathrm{~K}$. Table 1 reports the values of $a_{\sigma}$ which are obtained by adjusting equation (1) to computed values of $\sigma$.

Thermal conductivity $\kappa$ can be also described in terms of enthalpy provided Kirchhoff's heat potential $\varphi$ is used [22] :

$\kappa(T)=\frac{d \varphi}{d T}$

where $\kappa$ and $\mathrm{T}$ are respectively the thermal conductivity and the temperature.

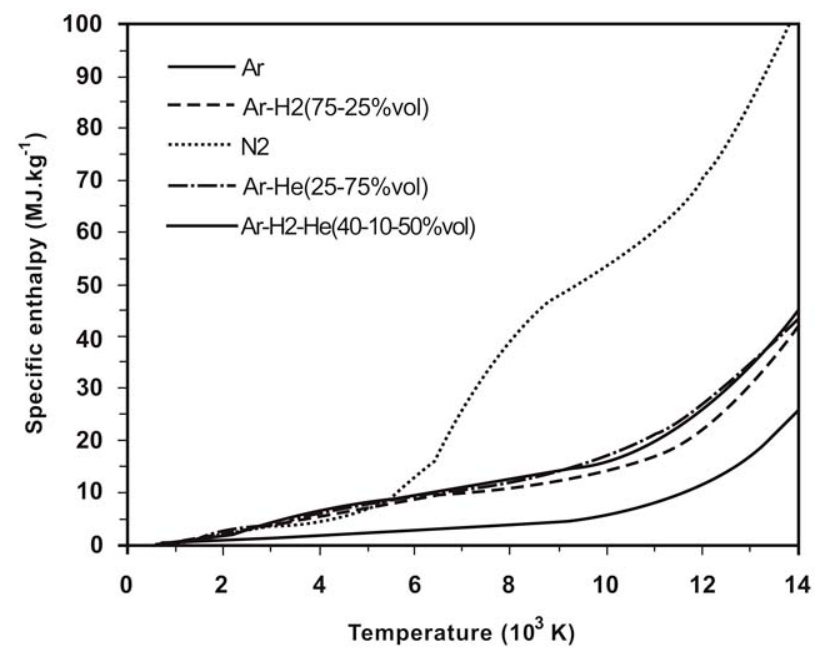

Fig. (2). Dependence on temperature of specific enthalpy of argon, argon-hydrogen (75-25\%vol), nitrogen, argon-helium (25-75\% vol), argon-hydrogen-helium (40-10-50\%vol) (after [21]).

Heat flux is $q=-\nabla \varphi$ and includes the contribution of energy transfers processes mainly due to the translational energy transfer resulting from collisions between particles and the reaction energy transfers which originate in dissociation and/or ionization reactions.

By integrating equation (2) for the preceding mixtures and arbitrarily vanishing the constant resulting from the integration, it can be shown that the calculated heat potential, 
in a first approximation, linearly varies over the enthalpy range of interest. Fig. (4) depicts the linear dependence of heat potential of various plasma mixtures on specific enthalpy. The proportionality constant between enthalpy and heat potential, $\mathrm{a}_{\varphi}$, is reported in Table $\mathbf{1}$.

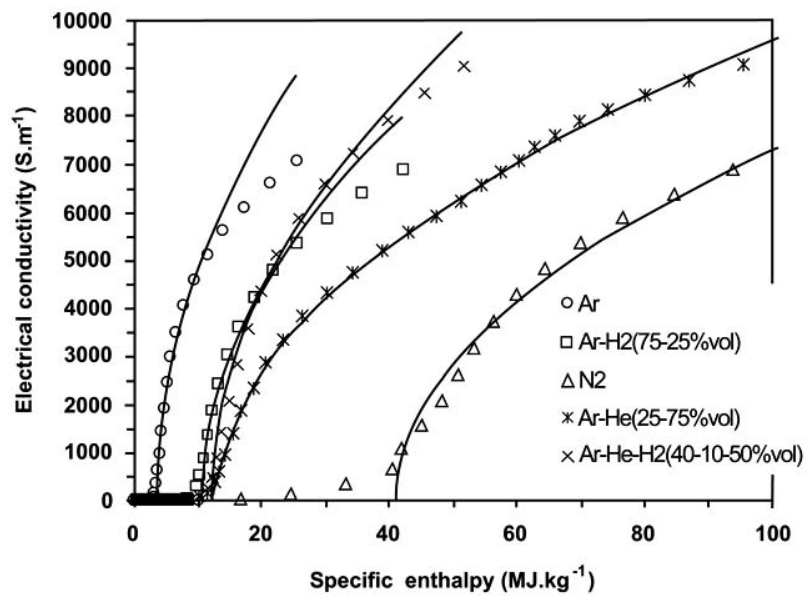

Fig. (3). Dependence on specific enthalpy of electrical conductivity of argon, argon-hydrogen mixture (75-25\%vol), nitrogen, argonhelium (25-75\%vol), argon-hydrogen-helium (40-10-50 \%vol). (Symbols: theoretical data; full lines: approximation following equation 1).

Table 1. Thermophysical Properties for Different Gases at Atmospheric Pressure: $h_{c}$ : Critical Enthalpy at Electrical Conduction Threshold, $a_{\varphi}$ Linear Coefficient Between Heat Potential and Specific Enthalpy, $a_{\sigma}$ : Coefficient Used for Electrical Conduction as a Function of Specific Enthalpy

\begin{tabular}{|c|c|c|c|}
\hline Plasma Gas & $\mathbf{h}_{\mathbf{c}}(\mathbf{M J} / \mathbf{k g})$ & $\mathbf{a}_{\boldsymbol{\varphi}}\left(\mathbf{1 0}{ }^{-4} \mathbf{k g} / \mathbf{m} . \mathbf{s}\right)$ & $a_{\sigma}\left(\mathbf{C} / \mathbf{V} \cdot \mathbf{m}^{2}\right)$ \\
\hline \hline $\mathrm{Ar}$ & 3.70 & 3.06 & 1.89 \\
\hline $\mathrm{Ar}-\mathrm{H}_{2}(75-25$ vol\%) & 10.40 & 7.06 & 1.42 \\
\hline $\mathrm{N}_{2}$ & 41.10 & 2.82 & 0.95 \\
\hline $\mathrm{Ar}-\mathrm{He}(25-75 \% \mathrm{vol})$ & 13.20 & 4.33 & 1.03 \\
\hline $\mathrm{Ar}-\mathrm{H}_{2}-\mathrm{He}(40-10-50 \% \mathrm{vol})$ & 12.14 & 4.31 & 1.56 \\
\hline
\end{tabular}

The dependence of the electrical conduction on enthalpy involving a critical threshold allows modeling the plasma in a plasma torch as a double layer such that, if $h>h_{c}$, electrical conduction takes place. Outside the $\mathrm{h}_{\mathrm{c}}$-surface, the electrical conductivity vanishes and a Cold Layer (CL) can be defined.

\subsubsection{Simplified Model}

The main purpose of this approach is to determine enthalpy radius profiles to deduce, from their integration over the area of section in the anode nozzle exit, the stationary characteristics of the plasma jet at the nozzle exit as function of easily measured experimental parameters (arc current, mean voltage, electrode thermal losses) and thermophysical properties of the plasma [23].

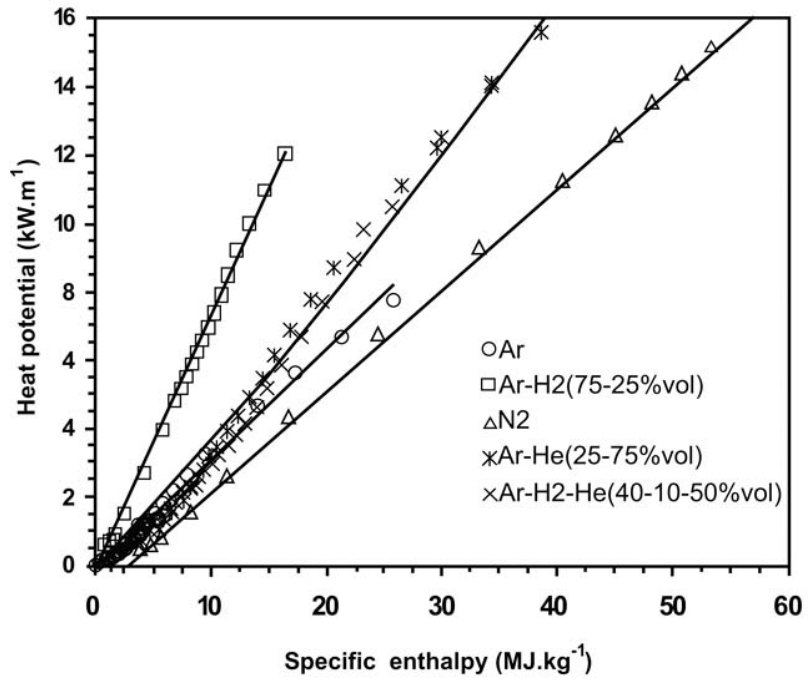

Fig. (4). Linear dependence of calculated heat potential as a function of calculated specific enthalpy of argon, argon-hydrogen mixture (75-25\%vol), nitrogen, argon-helium (25-75\%vol), argonhydrogen-helium $(40-10-50 \% \mathrm{vol})$. The slope of the straight lines is reported as $\mathrm{a}_{\varphi}$ in Table $\mathbf{1}$.

The flow is stationary and mainly axial where $u$ is the axial component of the plasma velocity. A mean radius, $r_{e}$, of the plasma is defined, so that $\mathrm{h}\left(\mathrm{r}_{\mathrm{e}}\right)=\mathrm{h}_{\mathrm{c}}\left(\right.$ or $\left.\mathrm{T}_{\mathrm{c}}=\mathrm{T}\left(\mathrm{r}_{\mathrm{e}}\right)\right)$.

The electrical power supplied to the torch after removing the electrode thermal losses in the cooling circuit is supposed to be converted into enthalpy flux. Neglecting the kinetic energy of the plasma flow, which represents a few percents of total energy in our conditions, an equivalent specific enthalpy $h_{0}$ can be defined :

$h_{0}=\frac{U I-P_{t h}}{\dot{m}}$

where $\mathrm{U}, \mathrm{I}, \mathrm{P}_{\mathrm{th}}$ and $\dot{m}$ are the measured mean values respectively of the arc voltage, of the arc current, of the electrode thermal losses and the gas mass flow rate.

$h_{0}$ is equivalent to the specific enthalpy averaged over the nozzle exit cross section :

$h_{0}=\frac{2}{R^{2}} \int_{0}^{R} r h(r) d r$

where $\mathrm{R}$ is the radius of anode nozzle.

As shown below, the equation (4) permits to link experimental measurements through $\mathrm{h}_{0}$ to theoretical enthalpy profiles determined in the arc column where electrical conduction takes place and the cold layer between the arc column and the anode electrode wall.

The specific enthalpy within the plasma results from a balance between the electric power input, dissipated by Joule heating, and thermal losses due to heat flow and radiation escaping from the plasma.

Thermal conductive losses $\left(\nabla^{2} \varphi\right)$ mainly depends on electrical power, enthalpy convection, and radiation. The 
introduction of heat potential permits to easily account for heat flow due to the proportional relationship between heat potential and specific enthalpy.

By grouping the convective specific enthalpy term, the Joule heating and the radiative losses terms as an overall constant source term, $\mathrm{s}_{\mathrm{h}}$, and by expressing the linearity between heat potential and specific enthalpy, the radial profile, $\mathrm{h}(\mathrm{r})$, at the nozzle exit can be deduced in the plasma $\left(0 \leq r \leq r_{e}\right)$ and in $\mathrm{CL}\left(r_{e} \leq r \leq \mathrm{R}\right)$ :

$$
\frac{1}{r} \frac{\partial}{\partial r}\left(r \frac{\partial h}{\partial r}\right)=\frac{s_{h}}{a_{\varphi}}
$$

In the plasma, Joule heating is always the dominant term to maintain the plasma discharge which results in $s_{h}<0$. Instead, in CL, Joule heating vanishes, radiative losses and convection of specific enthalpy are neglected so that the source term is set to zero in this region.

Equation (5) allows determining a very simple specific enthalpy parabolic profile within the plasma and a logarithmic one within CL. If $\xi$ is an non-dimensional variable such as $\xi=\left(\mathrm{r} / \mathrm{r}_{\mathrm{e}}\right)^{2}$, where $\mathrm{r}$ is the radial coordinate, the solutions of equation (5), which ensure the continuity of the specific enthalpy profile as well as its derivative when $\xi=1$, are :

For the plasma :

$h=h_{c}+\Delta h(1-\xi)$ for $0 \leq \xi \leq 1$

For $\mathrm{CL}$ :

$h=h_{c}-\Delta h \ln (\xi)$ for $1 \leq \xi$

where $\Delta h=\left|s_{h}\right| \cdot r_{i}^{2} / 4 a_{\theta}$

$\Delta h$ and $r_{e}$ are two unknowns and must be determined from two conditions : one concerning the overall thermal balance and the other one, the gas enthalpy at the anode wall whose temperature is sufficiently low so that $h(R)=0$.

The integration of equation (5), by using (6) and (7), and reduced variables $x=\frac{h_{e}}{h_{\varepsilon}}$ and

$y=\left(\frac{r_{s}}{R}\right)^{2}$, gives :

$x \ln y=\frac{1}{2} y-1$

This equation defines the overall thermal balance as nondimensional variables and is solved by using a NewtonRaphson method.

It must be underlined that the critical specific enthalpy, $\mathrm{h}_{\mathrm{c}}$, defined in equation 1, and the experimentally specific enthalpy $\mathrm{h}_{0}$ are close to each other, so that for most of experimental conditions, the ratio $x=h_{0} / h_{e}$ is close to unity.

Moreover, the derivation of the boundary condition, $h(\mathrm{R})$ $=0$, in terms of $\mathrm{x}$ and $\mathrm{y}$ variables, allows determining $\Delta \mathrm{h}$ :
$\Delta h=-\frac{h_{e}}{\ln y}$

The mean plasma radius, $r_{e}$, is evaluated from :

$r_{e}=R \sqrt{y}$

Finally, specific enthalpy profiles are fully determined from equations (9) and (10), which includes the thermophysical properties of plasma gases through $h_{c}$ and the measured thermal balances through $\mathrm{x}$, i.e. $\mathrm{h}_{0}$ with equation (3).

Heat flux per unit area $q_{w}$ at the anode electrode wall can be deduced assuming that main energy entering the cold layer is due to heat conduction at $r=r_{e}$ :

$q_{w}=-2 \pi r_{e} L\left(\frac{\partial \varphi}{\partial r}\right)_{r=r_{e}}=-2 \pi r_{e} a_{\varphi} L\left(\frac{\partial h}{\partial r}\right)_{r=r_{e}}$

Heat power $\Phi_{\text {conv }}$ convected to the anode wall of length $\mathrm{L}$ is:

$\Phi_{\text {conv }}=4 \pi a_{\varphi} L \Delta h$

The mean electric field of the arc column can also be written according to:

$l=2 \pi \int_{0}^{r_{r}} \sigma(r) E r d r=\pi r_{\theta}^{2} E a_{e} \int_{0}^{1} \sqrt{\left(h-h_{e}\right)} d \xi$

It comes:

$E=\frac{3 l}{2 \pi r_{e}^{2} a_{\sigma} \sqrt{\Delta h}}$

Fig. (5) shows good agreement between predicted convective power lost at anode electrode wall and those measured for three different anode nozzle extensions, $7 \mathrm{~mm}$ in diameter and 2, 3 or $5 \mathrm{~cm}$ in length, electrically insulated from the anode.

Fig. (6) presents the electric field theoretically deduced from the working parameters (equation 14) and measured by the use of a time of flight method [24]. The experimental values show a poor precision and only results obtained with nozzle diameters of 8 and $10 \mathrm{~mm}$ are relevant, but the general tendency is in agreement with the theoretical approach.

In the following, this model will be used to evaluate the plasma velocity at the nozzle exit which is modelled from a simplifed isentropic model for the plasma flow.

\subsubsection{Plasma Velocity}

After removing heat losses, the real plasma flow at the nozzle exit is assumed to be equivalent to an isentropic fictitious plasma flow presenting the same stagnation properties.

Following basic consideration of compressible fluid mechanics, the energy conservation is applied along a streamline crossing the nozzle exit section at a distance $r$ from the nozzle axis by using the Barré de Saint-Venant relationship for an isentropic and compressible flow: 
$\frac{1}{2} u^{2}(r)+\frac{\gamma}{\gamma-1} \frac{P_{a}}{\rho(r)}=h(r)$

where $u(r)$ is the axial plasma velocity at the nozzle exit, $P_{a}$ the pressure at the nozzle exit (atmospheric pressure in the present paper), $\rho(r)$ the plasma mass density, $\gamma$ the isentropic exponent, and $\mathrm{h}(\mathrm{r})$ the local specific enthalpy, previously defined by equations (6) and (7), and satisfying equation (4) which reflects the experimental conditions.

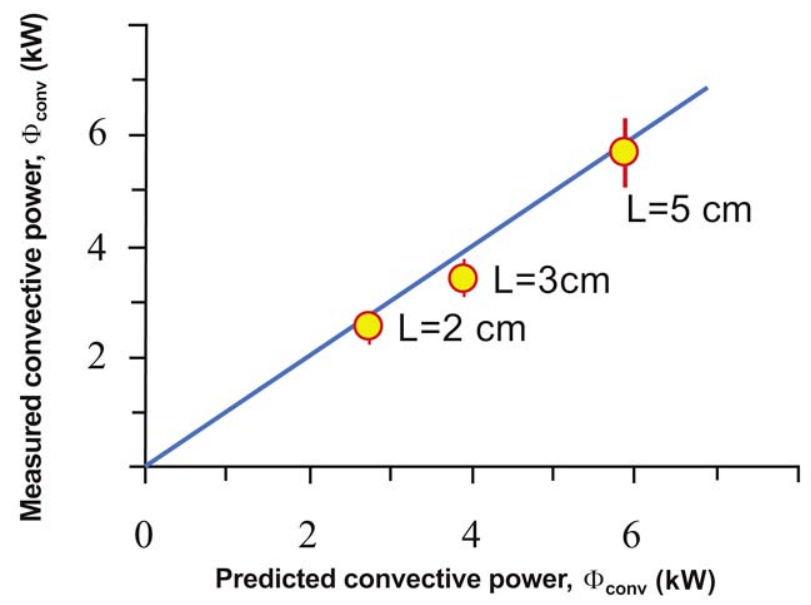

Fig. (5). Comparison between measured and predicted convective power lost at anode electrode wall using nozzle extensions. $\mathrm{L}$ is the nozzle length $-\left(\mathrm{Ar}-\mathrm{H}_{2}, 75 \mathrm{~mol} \% \mathrm{Ar}, \mathrm{I}=600 \mathrm{~A}\right)$.

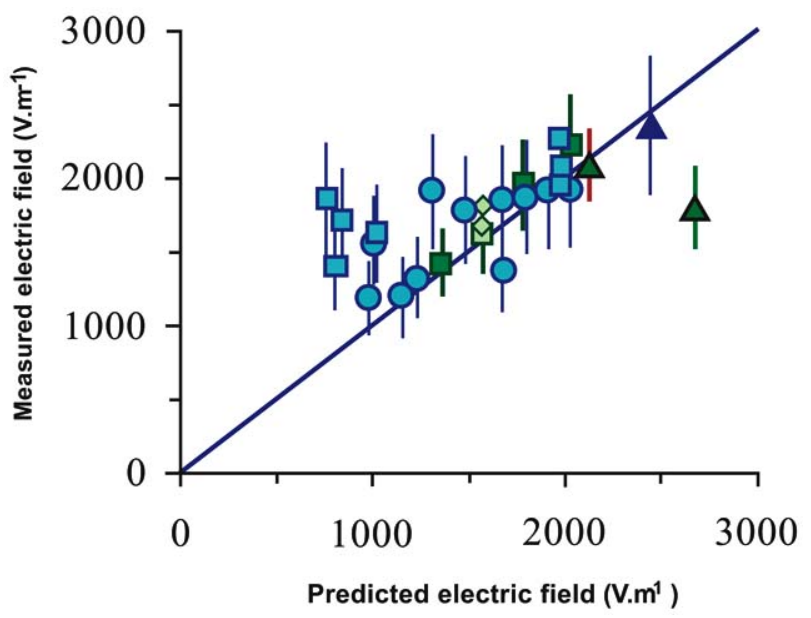

Fig. (6). Comparison between measured and predicted electric field for $\mathrm{Ar}-\mathrm{H}_{2}(75 \mathrm{~mol} \% \mathrm{Ar}) \mathrm{I}=300$ to $600 \mathrm{~A}$ - Nozzle diameters: 8 and $10 \mathrm{~mm}$.

Using $\dot{m}=\rho u S$, where $\mathrm{S}$ is the area of the nozzle cross section, equation (15) becomes:

$u^{2}(r)+\frac{2 \gamma P_{a} S}{(\gamma-1) \dot{m}} u(r)-2 h(r)=0$

This equation gives a very simple formula for the plasma velocity: $u(r)=v^{*}\left(\sqrt{1+\frac{2 h(r)}{v^{2}}}-1\right)$

where $v^{*}=\frac{y-1}{y} \frac{P_{a} s}{m}$

Note that in general $v^{* 2} \gg 2 h(r)$ and equation (17) is written $u(r) \approx h(r) / v^{*}$ within $10 \%$ of accuracy.

This preceding relationship can be used to define an averaged velocity $u_{0}$ by using $h_{0}$ :

$u_{0}=\frac{\gamma-1}{\gamma} \frac{\dot{m} h_{0}}{P_{a} S}$

The equation (18) accounts for the amount of thermal energy converted into fluid kinetic energy through the ratio $(\gamma-1) / \gamma$, where $\gamma$ is an averaged isentropic exponent which is directly linked to the plasma enthalpy or the ionization degree as shown by Burm et al. [25].

The equation (18) permits to estimate the averaged plasma velocity at the exit of the nozzle as function of experimental parameters. The isentropic exponent $\gamma$ is determined in the next section from an analysis of pressure contributions in the plasma process.

\subsubsection{Contributions of Pressure}

Absolute pressure $P_{z}$ measured on a point located on the gas feeding line upstream of the plasma torch $(\mathrm{M}$ point in Fig. 1) includes mainly four different contributions:

- the overpressure. $\Delta \mathrm{P}_{\mathrm{f}}$, due to the cold gas flow between the measurement point in the gas feeding line and the arc region,

- $\quad$ the isentropic overpressure, $\Delta P_{i s}$, which is the driving pressure. It is the same as that produced by an isentropic flow with a mean reservoir specific enthalpy $h_{0}$ equivalent to that really observed,

- the overpressure, $\Delta P_{v}$, due to the plasma viscosity within the nozzle. It will be admitted that it is proportional to the nozzle length $\mathrm{L}$,

- $\quad$ the magnetic overpressure $\Delta P_{m}$ due to the cathodic jet (Maecker effect) [20].

The reservoir pressure can easily be obtained by using the energy conservation of an isentropic flow and assuming that a small fraction of the specific enthalpy is converted into kinetic energy.

Thus, the isentropic overpressure, $\Delta P_{i s}=P_{0}-P_{a}$, has the following form:

$\Delta P_{i s}=\frac{(\gamma-1)}{\gamma} \frac{\dot{m}^{2} h_{0}}{2 S^{2} P_{a}^{2}}$ 
where $\mathrm{P}_{0}$ is the reservoir pressure corresponding to $\mathrm{h}_{0}$ and $\mathrm{P}_{\mathrm{a}}$ the atmospheric pressure, $\dot{m}$ the total gas mass flow rate, and $\mathrm{S}$ the section of the anode nozzle.

Assuming a loss pressure proportional to the nozzle length $\mathrm{L}$ for $\Delta P_{v}$, it can be shown:

$\Delta P_{p}=\Delta P_{m}+\frac{\gamma-1}{\gamma} \frac{\dot{m}^{2} h_{0}}{2 S^{2} P_{a}^{2}}(1+\alpha L)$

where $\Delta P_{p}=P_{s}-\left(P_{a}+\Delta P_{f}\right)$.

Measuring $\Delta \mathrm{P}_{\mathrm{f}}$ by the use of pressure transmitter and $\mathrm{h}_{0}$, the previous equation has been checked as shown in Fig. (7). It represents the dependence of $\Delta P_{p}$ on $\dot{m}^{2} h_{0}$ for $\mathrm{Ar}-\mathrm{H}_{2}$ plasma and arc current ranging between 350 and $600 \mathrm{~A}$. The coefficient $\alpha$ can be experimentally determined by using different anode-nozzle lengths [23]. Consequently, from the slope of curves, the isentropic coefficient can be determined. The ordinate, when the term $\dot{m}^{2} h_{0}$ vanishes, gives the magnetic overpressure $\Delta P_{m}$. These values corresponding to 5,6 and $7 \mathrm{~mm}$ nozzle diameters respectively are 1,8 and $4.10^{3} \mathrm{~Pa}$ and with an accuracy of $\pm 3.10^{3} \mathrm{~Pa}$.

These values are not sufficiently reliable to be interpreted as a function of diameter or arc current intensity. However, it has to be noted that the mean measurement, $6.10^{3} \mathrm{~Pa}$, is consistent with the value given by Gauvin [26] for transferred arcs, namely 2.5.10 $\mathrm{Pa}$.

Following the accuracy of measurements, the isentropic exponent is found to vary between 1.15 and 1.19 . This value is consistent to that of Burm et al. [25] who recommends 1.16 for plasmas with ionisation degree higher than $5 \%$.

The equation (17) can be then used to calculate the center line plasma velocity, $\mathrm{u}_{\max }$, defined such as:

$u_{\max }=v^{*}\left(\sqrt{1+\frac{2 h(0)}{v^{* 2}}}-1\right)$

with $h(0)=h_{\varepsilon}+\Delta h$.

A mean value of $\gamma=1.17$ for an $\mathrm{Ar}-\mathrm{H}_{2}(75-25 \% \mathrm{vol})$ is used. A comparison with previous plasma jet velocity measurements [27] is shown in Fig. (8). The internal nozzle diameters are $6,7,8$, and $10 \mathrm{~mm}$, the arc current varies between 400 and $600 \mathrm{~A}$ for an $\mathrm{Ar}-\mathrm{H}_{2}$ plasma (45-15 slm). The ratio $(\gamma-1) / \gamma$ gives the proportion of available energy converted into mechanical energy. It is then expected than plasma jet using helium should present higher velocities than plasma involving hydrogen at constant mean specific enthalpy.

The quantities $h_{c}$ and $\Delta h$ are calculated as explained in the model above according to the experimental conditions of plasma velocity measurements.

Good agreement is observed in Fig. (8) between calculations and measurements performed over a wide range of experimental conditions.

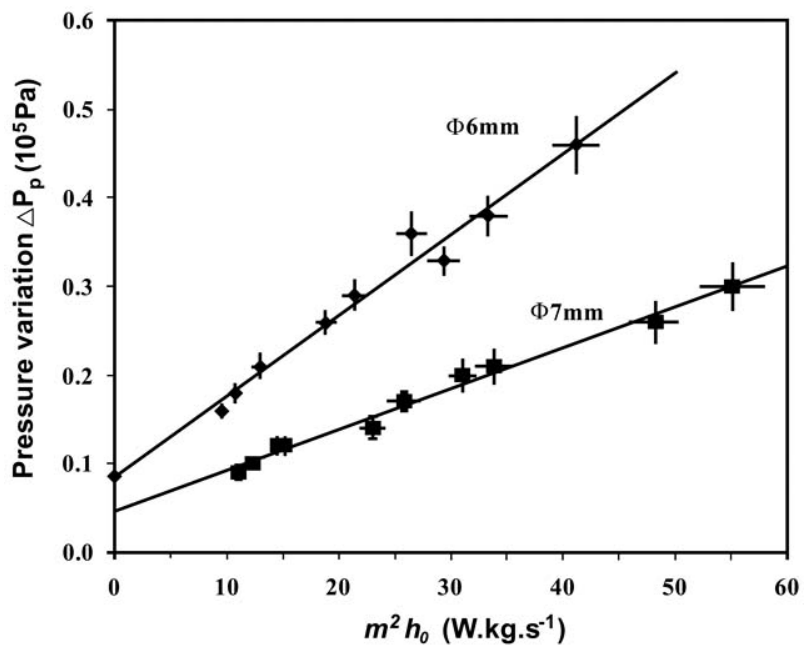

Fig. (7). Pressure variation $\Delta P_{p}=P_{z}-\left(P_{a}+\Delta P_{f}\right)$ as function of the product $\dot{m}^{2} h_{0}$ where $\mathrm{P}_{\mathrm{t}}, \mathrm{P}_{\mathrm{a}}$ and $\Delta P_{f}$ are respectively the total pressure, the atmospheric pressure and the pressure loss due to the plasma gases for internal nozzle diameters of 6 and $7 \mathrm{~mm}$.

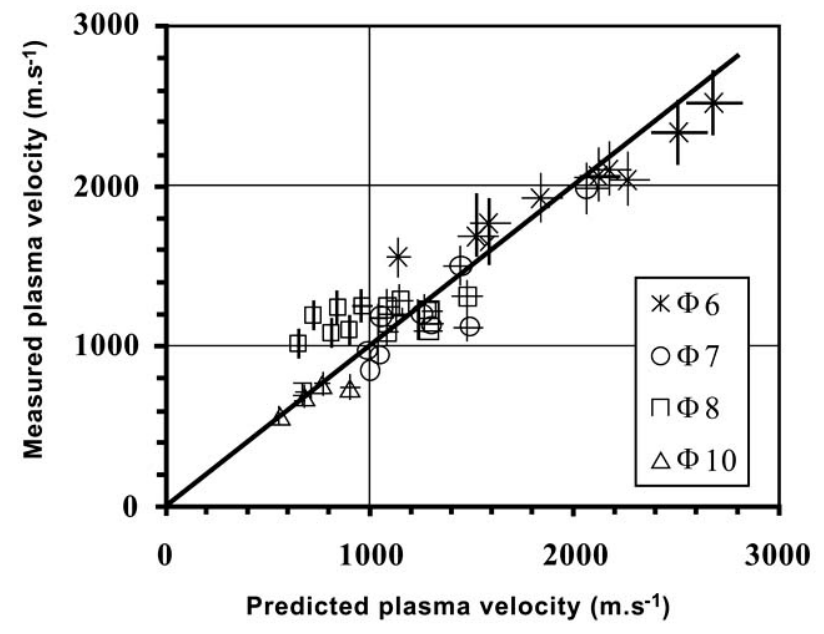

Fig. (8). Comparison between measurements [27] of the center line plasma jet velocity at the nozzle exit of a dc plasma torch for different inner nozzle diameters, d, i.e. 6, 7, 8 and $10 \mathrm{~mm}\left(\mathrm{Ar}-\mathrm{H}_{2}\right.$, $45 / 15 \% \mathrm{vol})$ and its calculation in the same conditions following the present model.

Even though this simplified model is very helpful to have a better understanding on the influence of operating parameters on time averaged plasma properties, the time dependence of the latter on solid or liquid precursors have to be investigated as explained below. The next section describes the electric arc instabilities in a dc plasma torch without presenting a complete review of transient and 3D modeling of such instabilities. This was very recently done in a review paper [18].

\subsection{Electric arc Instabilities}

The development of coating elaboration processes involving electric arcs depends on process stability and the capacity to ensure a constant reproducibility of coatings properties. This is particularly important when considering 
the plasma treatment of submicron or nanosized particles. Thermal and dynamic characteristic times which govern the energy and momentum transfers between plasma and particles are linked to the diameter of the latter. For example, the characteristic time of momentum transfer between the plasma and a solid particle under the application of the drag force due the plasma flow is simply given by $\tau_{v}=\rho_{\text {part }} d^{2} / 18 \mu_{p}$ where $\rho_{\text {part }}, d, \mu_{p}$ are respectively the solid particle density, the particle diameter and the plasma viscosity [28]. If $\mathrm{d}=30 \mu \mathrm{m}, \tau_{v}=700 \mu \mathrm{s}$, with a mean plasma temperature of $10^{4} \mathrm{~K}$. If $\mathrm{d}=1 \mu \mathrm{m}, \tau_{y}=0.8 \mu \mathrm{s}$. Plasma viscosity is found in [21]. In the next section, it is shown that the period of arc fluctuations is about $200 \mu \mathrm{s}$ depending on operating conditions. Thus, this simple evaluation shows that submicron particles used in Suspension Plasma Spraying closely follow plasma instabilities and will have non-homogeneous plasma treatment. Instead, the influence of arc instabilities on particles with tens of microns in diameter is smoothed. Consequently, unsteady and non uniform plasma states produce an inhomogeneous plasma treatment of solid particles which will be all the more important as particle diameter decreases [29]. In case of conventional plasma spraying where particles with tens of microns in diameter are injected, the effect of plasma instabilities is smoothed with respect to suspension plasma spraying. However, they are important in SPS process as shown below.

The plasma fluctuations cause local variations of velocity and specific enthalpy fields. Their origin can be found in the fluctuations of instantaneous power dissipated by Joule heating from the electric arc within the plasma forming gases due to arc voltage variations. Three main modes of voltage fluctuations are usually described in blown arc plasma torches and were first reported by Wutzke et al. [30]. The "steady mode" corresponds to a constant arc voltage, i.e. a stable attachment of the electric arc root at the anode wall. The "takeover mode" is associated with a quasi-sinusoidal signal of the arc voltage and is observed when using monatomic plasma forming gases (Argon, Helium). The "restrike mode" corresponds to an elongation of the arc column followed by an upstream rearcing phenomenon through the cold boundary layer between the arc column and the anode wall (Fig. 9). A restrike signal is a typical sawtooth shaped signal. This latter mode is probably the most studied one because it is currently observed when using $\mathrm{Ar}$ $\mathrm{H}_{2}$ mixture as plasma forming gases. The chemical composition of plasma forming gases not only affects the electric arc properties but also the solid particles injected within the plasma jet. The addition of hydrogen leads to an increase of the electric field of the column arc and consequently of the mean arc voltage. This is mainly due to the dissociation of hydrogen molecules which increases thermal radial losses compensated by the increase of the Joule heating source $\left(\sigma \mathrm{E}^{2}\right.$, where $\sigma$ and $\mathrm{E}$ are the electrical conductivity and the electric of the arc column) to ensure the arc current flow. The available input energy is therefore enhanced to plasma treat solid particles. Moreover, due to the high thermal conductivity of $\mathrm{H}_{2}$, the plasma/solid particles thermal transfers are improved At last, the use of argon as plasma forming gases is favourable to plasma/solid particles momentum transfers to perform an efficient spraying of particles. In the Wultzke et al.'s works, it is suggested that the fluctuation modes depends on boundary layers properties and is associated with the attachment mode of the arc root (diffuse or constricted, see also [31]). The boundary layer surrounding the arc participates to a large extent in the process of arc instabilities particularly in the rearcing phase for the Restrike mode. During elongation of the arc column, the electric field in the boundary layer (electrically poorly conductive) between the arc column and the anode wall increases. When this electric field reaches a critical threshold, an upstream arc rearcing occurs and corresponds to a sudden formation of a new electrically conductive path for electrons. The physical mechanism of this arc reattachment is not still understood and is sometimes associated with a streamer-type discharge [32].

The combined effect of hydrodynamic (drag) forces and magnetic forces provoke arc motions and stretching of the arc current lines. These effects are particularly important close to the arc root at the anode wall because the curvatures of current lines create unbalanced magnetic forces displacing the arc [33].

When a pure saw-tooth shape arc voltage signal is observed, the previous description is appropriate. However, in many cases, arc voltage signals are complex and present a superimposition of the restrike mode and the so-called Helmholtz mode which will be described below $[34,35]$.
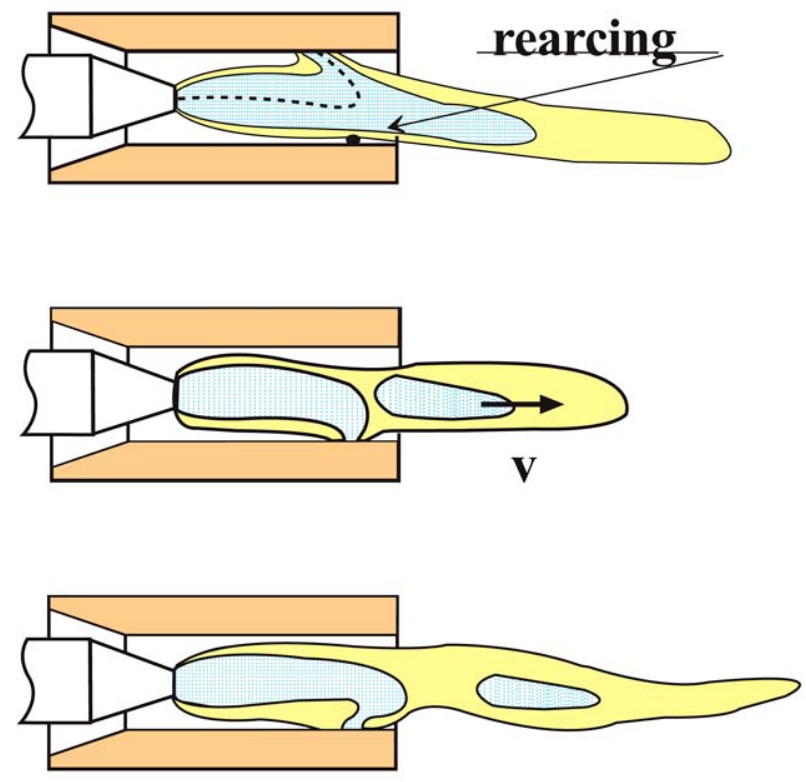

Fig. (9). Representation of elongation and rearcing of the arc column of a dc plasma torch: Restrike mode.

\subsubsection{Arc Voltage Signals-Temporal Features}

Fig. (10) shows the time resolved $(0.5 \mu \mathrm{s} / \mathrm{sample})$ measurement of the voltage obtained with F4 commercial (Sulzer Metco) dc plasma torch and an anode nozzle presenting a $6 \mathrm{~mm}$ inner diameter, fed with a $60 \mathrm{slm}$ (standard liters per minute) argon flow rate and a current of $500 \mathrm{~A}$. The plasma torch geometry corresponds to Fig. (1). For pure argon, the voltage presents a mean value around 30 
$\mathrm{V}$ and an undulation of approximately $5 \mathrm{~V}$ peak to peak. Fig. (10) also shows the voltage recorded for an argon-hydrogen mixture $(45-5 \mathrm{slm})$ and a current of $300 \mathrm{~A}$ with the same plasma torch. Both the mean value and the fluctuating components have increased compared to the signal obtained with pure argon, with respective values of $55 \mathrm{~V}$ and $60 \mathrm{~V}$ peak to peak. On both signals it can be observed the presence of an almost periodic component, approximately $300 \mu \mathrm{s}$ in period, on which are superimposed more randomly distributed events, which durations are spread over a few tens of $\mu$ s range. In the case of Argon-hydrogen, the events, which present very sharp falls, are related to the restrike mode.

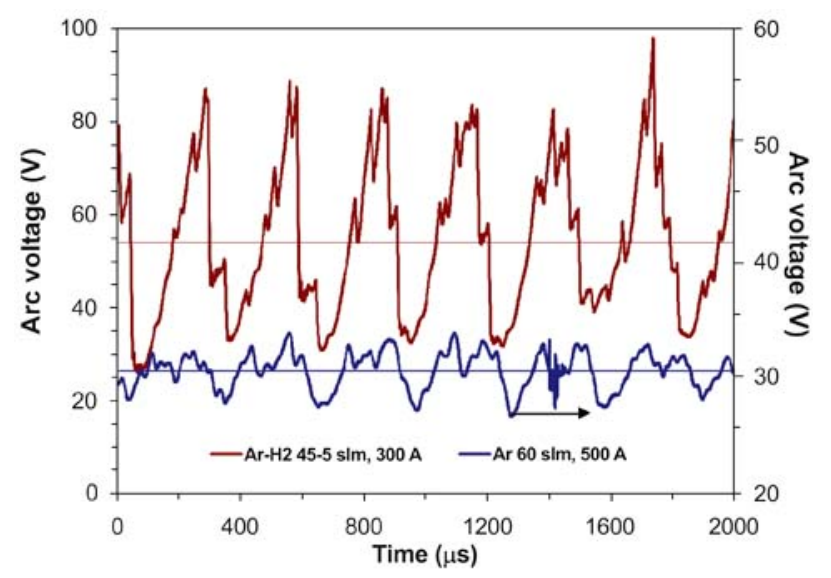

Fig. (10). Arc voltage signals of de plasma torch (F4 Sulzer Metco) operating with pure argon and $\mathrm{Ar}-\mathrm{H}_{2}$ mixture.

\subsubsection{Arc Voltage Signals-Spectral Features}

For the spectral analysis, we focus on the low frequency rage $(3-8 \mathrm{kHz})$ and fix maximum frequency, $\mathrm{f}_{\max }$, of $10 \mathrm{kHz}$. The number of samples is 65000 samples/signal.

In order to compare spectra obtained in different experimental conditions, the power spectra were normalized with respect to the variance of the voltage. The instantaneous voltage, $U(t)$, is the sum of the mean value, $V$, and of the fluctuating component, $v(t)$. The average squared quantities are linked so that,

$$
\left\langle U^{2}\right\rangle=V^{2}+\left\langle v^{2}\right\rangle
$$

where the last term, $\left\langle v^{2}\right\rangle$, is the variance of the voltage. The power spectrum, $\Phi(f)$, of the voltage fluctuating component, $v(t)$, that is the squared amplitude of its Fourier components, is such that,

$$
\int_{0}^{f_{\max }} \Phi(f) d f=\left\langle v^{2}\right\rangle
$$

and will be expressed in $\mathrm{V}^{2} / \mathrm{Hz}$ in the following figures.

Fig. (11) presents the power spectrum of the signal corresponding to conditions mentioned in Fig. (10) for pure argon.

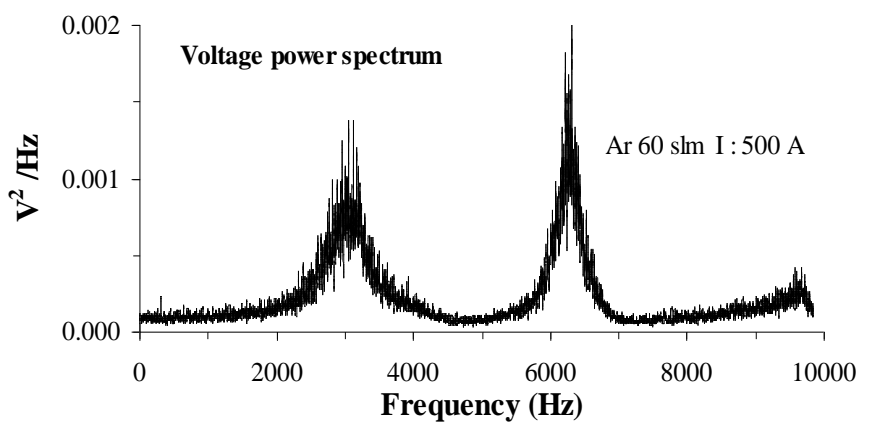

Fig. (11). Voltage power spectrum for argon.

The two lines in that spectrum are rather large, the high frequency one being an image of the low frequency one by a doubling frequency process. The slight rising slope of the high frequency part of the spectrum suggests that other components should exist at frequencies higher than the cut off imposed by the chosen sampling rate. The spectrum in Fig. (12) is obtained for Ar- $\mathrm{H}_{2}$ mixture as in Fig. (10).

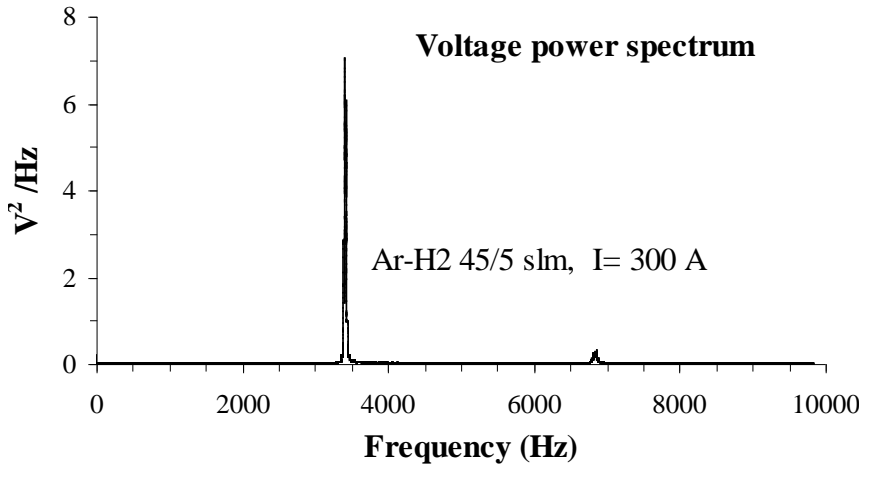

Fig. (12). Voltage power spectrum for an argon-hydrogen mixture.

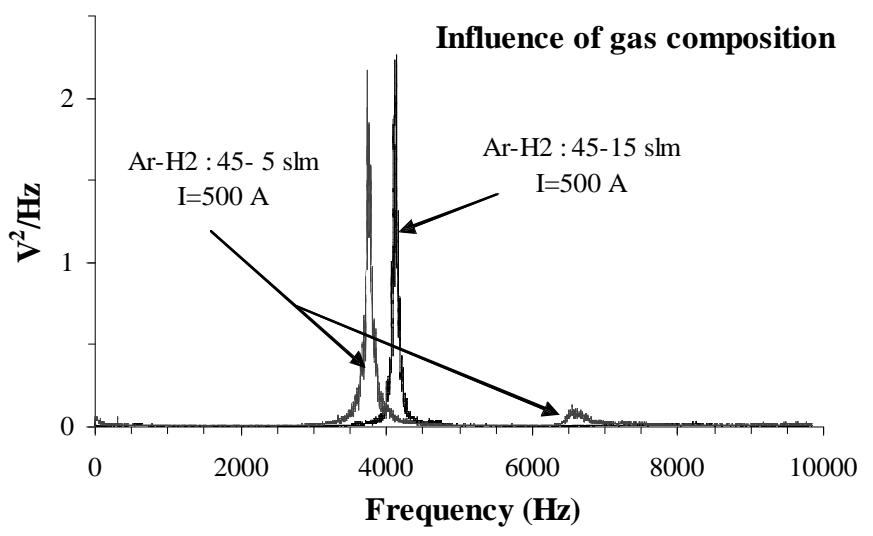

Fig. (13). Effect of gas composition on voltage spectrum.

A very sharp line can be identified, presenting a maximum value increased by more than three orders of magnitude, compared to Fig. (11). The effect of the gas composition is shown in Fig. (13), where the voltage spectra, obtained for the same arc current, are plotted for two argonhydrogen mixtures, corresponding to flow rate of 45-5 slm and $45-15 \mathrm{slm}$. In reality, the frequency shift observed when increasing the hydrogen content is also due to a significant increase of the torch voltage accompanied, by an increase of the specific enthalpy. 
The comparison between Figs. $(\mathbf{1 2}, \mathbf{1 3})$ shows that an increase of the arc current shifts the peaks towards the high frequencies, but also strongly attenuates the amplitude of the lines.

The evolutions of these power spectra are interpreted in terms of Hemholtz resonance coupled with the restrike mode. The next section basically describes the Helmholtz resonator.

\subsubsection{Helmholtz Resonator}

\subsubsection{Principle}

The basic Helmholtz resonator is based on the oscillatory motion of a gas mass contained within a neck of length $\mathrm{L}$ and section area S (Fig. 14). Under the effect of external mechanical excitations, the mass displacement adiabatically compresses and expanses the gas within the resonator with volume $\mathrm{V}_{\mathrm{g}}$. The motion of this mass is therefore linked to pressure in volume $\mathrm{V}_{\mathrm{g}}$ through the adiabatic law of gases. A simple differential equation can be derived highlighting the fundamental frequency of oscillation $\omega_{0}$ :

$$
\frac{d^{2} p}{d t^{2}}+\omega_{0}^{2} p=0
$$

$p$ is the pressure variation in the resonator and

$\omega_{0}=c_{0} \sqrt{\frac{S}{L V_{g}}}$

$c_{0}$ is the sound velocity.

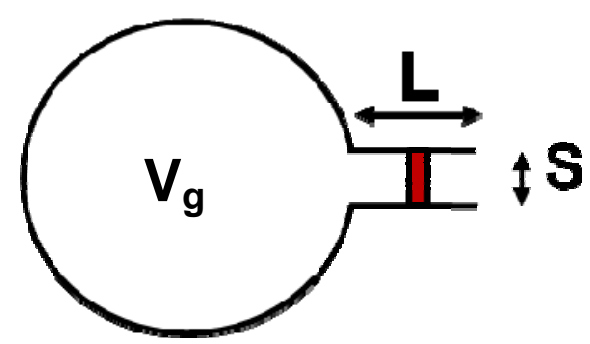

Fig. (14). Helmholtz resonator.

2.3.3.2. Simplified Approach of de Plasma Torch as Resonator

The plasma torch is a F4 commercial torch (Sulzer Metco) and is schematically represented in Fig. (1).

Plasma forming gases are injected through the injection ring in the cathode cavity, is heated by the electric arc from the cathode tip and expelled at the nozzle exit. Consequently, the F4 plasma torch resembles a Helmholtz resonator where the volume $V_{g}$ in Fig. (1) represents the cathode cavity from the injection ring to the cathode tip and the neck is associated with the distance between the cathode tip and the exit of the anode nozzle.

Since in Fig. (10), restrike events of electric arc are superimposed to more pronounced oscillations, we assume that the restrike mode excites the resonator.
By applying a similar method as in previous section to the plasma mass, a simplified motion of plasma mass can be written and a Helmholtz frequency defined:

$f_{1}=\frac{1}{2 \pi} \sqrt{\frac{\gamma_{g} p_{g}}{\rho_{p}}} \sqrt{\frac{S}{L V_{g}}}$

where $p_{g}, \gamma_{g}, \rho_{p}$ are respectively the mean pressure within the cathode cavity, the isentropic exponent of plasma forming gases, plasma density.

Note that the relationship does not include anymore the sound velocity and accounts for the geometrical data of the plasma torch.

A similar equation can be obtained from an acoustic approach of the cathode cavity presented in the next section.

\subsubsection{Acoustic Approach}

As shown above, volumes and lengths are important geometrical data when defining the Helmholtz resonator. We have proposed a simplified and realistic model of the acoustic resonance considering an equivalent resonator and only axial motions [34].

Denoting $\mathrm{x}$ the axial coordinate, where $\mathrm{x}=0$ corresponds to the wall of the injection ring, the evolution of the cross section, through which the gas is flowing, is denoted $S(x)$ and is calculated after the torch inner geometry. Then, a radius $r(x)$ is defined such that $S(x)=r^{2}(x)$.

The evolutions of $+r(x)$ and $-r(x)$ are plotted in Fig. (15), so that they define the shape of an equivalent resonator presenting the same volume and the same total length than the real electrode configuration. This resonator geometry is then simplified and is decomposed into three cylindrical sections, labeled 1, 2 and 3 in Fig. (15). We theoretically evaluate the resonance frequencies of such a complex cavity, assuming in addition, that the pressure perturbations can only propagate as plane waves travelling along the $\mathrm{x}$ direction.

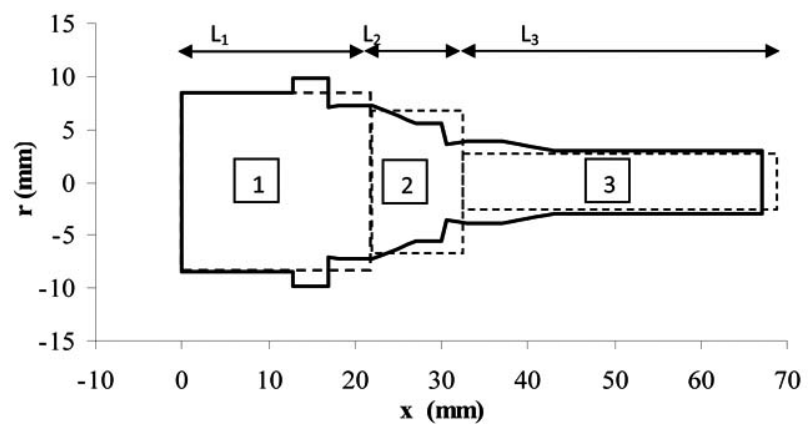

Fig. (15). Resonator configuration equivalent to the torch. Solid line : contours defined by equation (3), dotted line : simplified configuration used for the model. $\mathrm{L}_{3}$ is the channel length.

In each of the three regions of the simplified resonator, the acoustic pressure, $\mathrm{p}(\mathrm{x}, \mathrm{t})$, and acoustic velocity, $\mathrm{u}(\mathrm{x}, \mathrm{t})$ are the sum of two waves, travelling in two opposite directions. The local acoustic impedance [36] in region 1 , which corresponds to $0<\mathrm{x}<\mathrm{L}_{1}$, is 
$Z_{1}(x)=\frac{p(x, t)}{S_{1} u(x, t)}=\frac{\rho_{g} a_{g}}{S_{1}} \frac{1+R_{1} e^{2 j k_{0} x}}{1-R_{1} e^{2 j k_{0} x}}$

where $a_{\rho}$ and $\rho_{g}$ are respectively the speed of sound and the mass density of the cold gas, $R_{1}$ is the reflection coefficient and $k_{0}$ is the wave vector modulus associated with the frequency, $\mathrm{f}$. The latter is defined by $k_{0} a_{g}=2 \pi f$.

Using a similar expression in the next cold gas section, $\mathrm{L}_{1}<\mathrm{x}<\mathrm{L}_{1}+\mathrm{L}_{2}$, and for the region containing the plasma, $\mathrm{L}_{1}+\mathrm{L}_{2}<\mathrm{x}<\mathrm{L}_{1}+\mathrm{L}_{2}+\mathrm{L}_{3}$, acoustic impedances are obtained in each regions.

The resonance conditions are associated with the impedance continuity at $\mathrm{x}=\mathrm{L}_{1}$ and $\mathrm{x}=\mathrm{L}_{1}+\mathrm{L}_{2}$, otherwise the waves are vanishing by phase mixing.

This expression with the assumption that the ratio gas sound velocity is much smaller than that of plasma, it comes for the Helmholtz frequency [34]:

$\frac{X}{f_{1}^{2}}=a_{H}+b_{H} \frac{f_{1}^{2}}{a_{g}^{2}}$

where

$X=\gamma_{g} \frac{p_{p}}{\rho_{p}}$

and $\mathrm{a}_{\mathrm{H}}=4 \pi^{2} \frac{V_{g} L_{3}}{S_{3}}$ and $\mathrm{b}_{\mathrm{H}}=\frac{16 \pi^{4}}{3}\left[\frac{S_{1} L_{3} L_{1}^{2}}{S_{3}}\left(L_{1}+3 \frac{S_{1}}{S_{2}} L_{2}\right)\right]$ are two constant factors only depending on the torch geometry. $S_{i}$ is the area of ith section of ith region $(i=1,2,3)$ in Fig. (15). Note that if $b_{H}$ is zero, equation (28) is the same as equation (26).

\subsubsection{Results}

The relationship (28) was tested for arc currents between 400, 500 and $600 \mathrm{~A}$ and 45-5, 45-10 and 45-15 slm argonhydrogen mixtures. Pressure in the cathode cavity $p_{g}$ was experimentally determined as $\left(p_{t}+p_{a}\right) / 2$ as explained in section 2.2.2.2. Plasma density $\rho_{p}$ was obtained from experimental measurements of the mean enthalpy $h_{0}$ (equation 3) and from thermodynamic data [21] to deduce $\rho_{p}$. The Helmholtz frequency $f_{H}$ was measured from power spectra of the plasma torch arc voltage.

The influence of the volume of the cathode cavity was studied in the standard configuration, with an additional injection ring to reduce the volume, and any injection ring to increase the volume. The standard volume is equal to $\mathrm{V}_{\mathrm{g}}=6.1$ $\mathrm{cm}^{3}$. When removing, the injection ring, the cathode cavity increases up to $V_{g}=9.1 \mathrm{~cm}^{3}$. When a boron nitride additional ring is added to reduce the cathode cavity, the volume is $\mathrm{V}_{\mathrm{g}}=3.8 \mathrm{~cm}^{3}$.

We have plotted, in Fig. (16), $X / f_{1}^{2}$ as a function of $f_{1}^{2}$ for the different cathode volumes. Fig. (16) shows present a consistent distribution of experimental points following the previous simplified model. Note that $\mathrm{b}_{\mathrm{H}}$ is almost zero. In Fig. (17), power spectra of the arc voltage are shown for the three cathode cavity configurations. It can be seen that when the volume is large ("no ring"), the amplitude of the peak is high and the full width at half maximum (FWHM) is weak. When volume decreases, the amplitude decreases and FWHM increases. This means that the quality factor of the resonator decreases and the arc oscillation is damped. Moreover, the Helmholtz frequency increases as predicted by the equation (26).

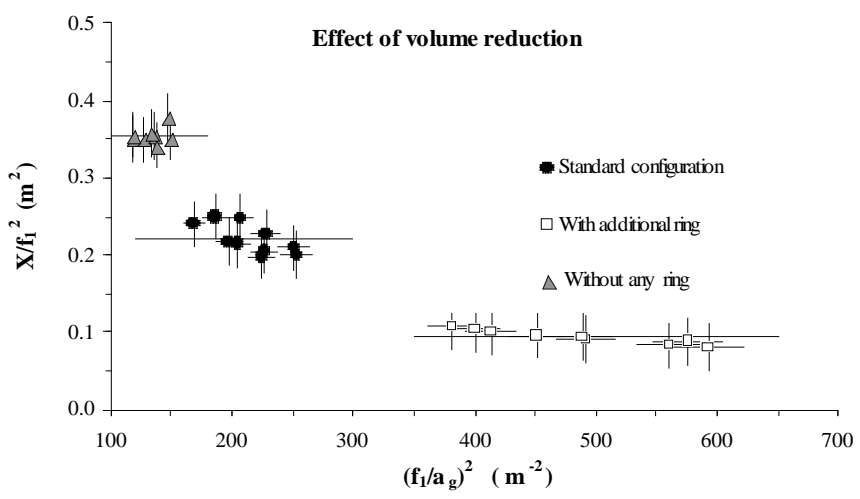

Fig. (16). Effect of injection ring for the F4 geometry plasma torch. Plasma gas : Ar- $\mathrm{H}_{2}$, Arc current 400, 500, 600 A. (no ring $: \mathrm{V}_{\mathrm{g}}=9.1$ $\mathrm{cm}^{3}$, Standard : $\mathrm{V}_{\mathrm{g}}=6,1 \mathrm{~cm}^{3}$, additional ring : $\left.\mathrm{V}_{\mathrm{g}}=3.8 \mathrm{~cm}^{3}\right)$.

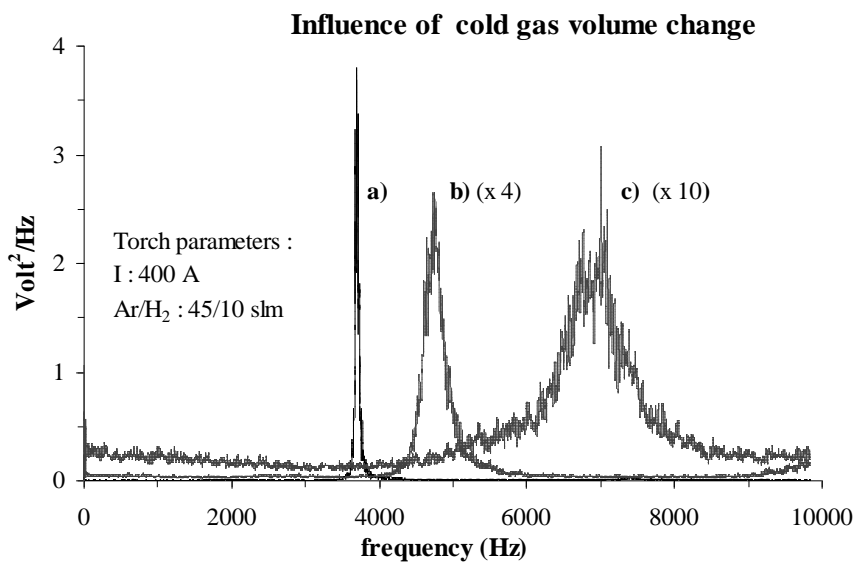

Fig. (17). Evolutions of the voltage power spectrum. The lines are shifted towards the high frequencies as the $\mathrm{V}_{\mathrm{g}}$ volume is lowered. a) no ring : $\mathrm{V}_{\mathrm{g}}=9.1 \mathrm{~cm}^{3}$, b) Standard: $\mathrm{V}_{\mathrm{g}}=6,1 \mathrm{~cm}^{3}$, c) additional ring : $\mathrm{V}_{\mathrm{g}}=3.8 \mathrm{~cm}^{3}$.

\subsubsection{Pressure Measurement in Cathode Cavity}

When assuming that a dc plasma torch behaves like a Helmholtz resonator, it is implicitly suggested a strong coupling between the arc voltage and pressure in the cathode cavity. To check this assumption, dynamic pressure was measured by the use of piezoresistive sensor (ENDEVCO, $320 \mathrm{kHz}$ bandwidth and $2 \mathrm{~mm}$ in diameter) inserted in the cathode cavity. Arc voltage and dynamic pressure of cold gas in the cathode cavity was simultaneously recorded by a PCI National Instrument card controlled by Labview Software.

Fig. (18) shows the simultaneous measurement for a Ar$\mathrm{H}_{2}(90 \mathrm{~mol} \%)$ plasma at $400 \mathrm{~A}$. It can be observed pressure of cold gas in cathode cavity has the same signal structure as arc voltage. This is also confirmed in Fig. (19) where the corresponding power spectra are presented. The time shift $(\sim 100 \mu \mathrm{s})$ between arc voltage and pressure corresponds to time propagation from the cathode tip to the sensor location. 
These figures confirm the coupling between pressure of cold gas in the cathode cavity and the arc voltage.

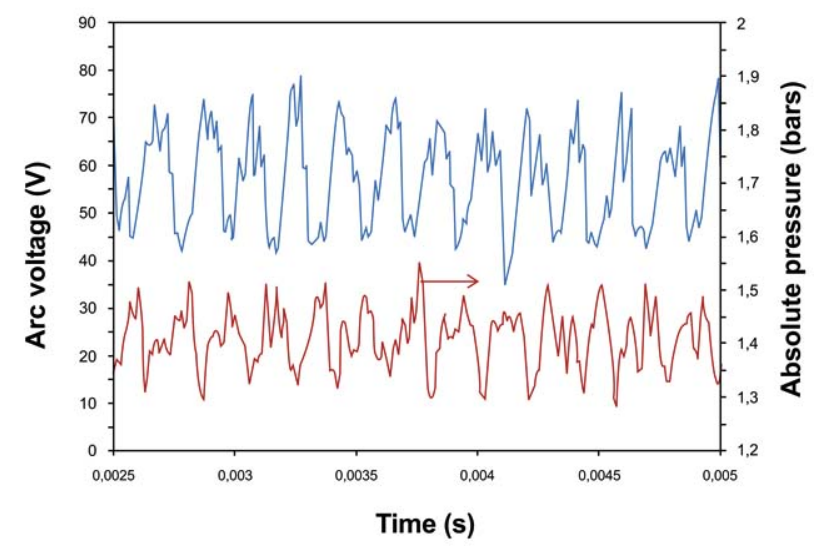

Fig. (18). Arc voltage and absolute pressure in the cathode cavityAr- $\mathrm{H}_{2}(90 \mathrm{~mol} \% \mathrm{Ar}), 400 \mathrm{~A}$, internal nozzle diameter $6 \mathrm{~mm}$.

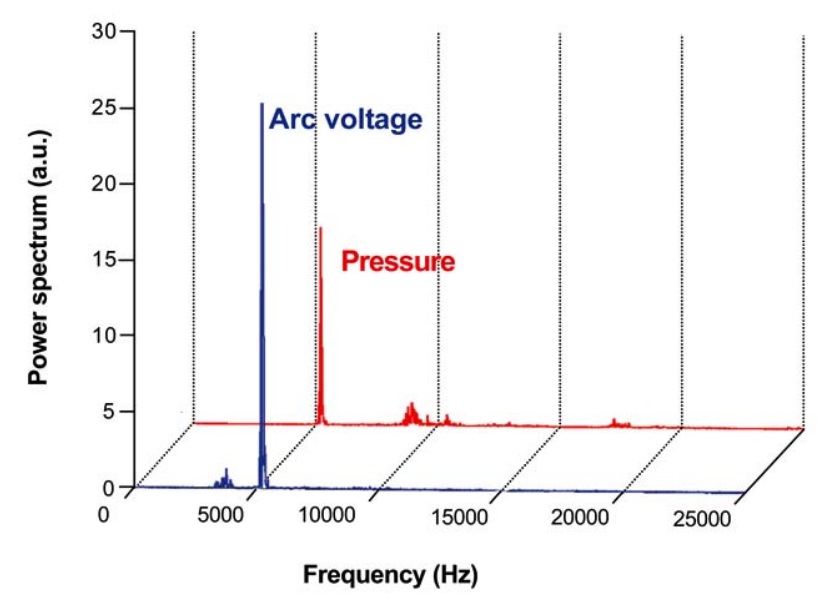

Fig. (19). Power spectra of signals in Fig. (18).

The coupling between pressure of cold gas in the cathode cavity and the arc voltage shows that the evolutions power spectra in Figs. (11-13) cannot be simply interpreted by the use of the "restrike model". This coupling is all the more important as the cathode volume is large. When operating parameters are changed (arc current, hydrogen flow rate), pressure and plasma density are modified, and the frequency of arc voltage fluctuations is approximately given by equation (26).

As a conclusion, the main origin of arc instabilities is found in mechanical resonance phenomena between the electrical arc and the cold gas in the rear part of the plasma torch. In particular, the amplitude of arc voltage variations is directly connected to the volume of the cathodic cavity. Works are now in progress to limit these effects on the arc voltage and therefore on momentum and thermal transfers between the plasma and the solid particles. As shown below, the arc instabilities not only influences momentum and thermal transfers between solid particles and plasma as explained above, but also is responsible for the dispersion of suspension fragmentation processes.

\section{FINELY STRUCTURED COATINGS}

\subsection{Influence of Plasma Instabilities in Suspension Plasma Spraying}

Suspension plasma spraying (SPS) is an emerging technology and an alternative to atmospheric plasma spraying (APS) to manufacture thinner layers (from 5 to 50 $\mu \mathrm{m}$, average values) $[37,38]$.

In Suspension Plasma Spraying process, a suspension is injected within a dc plasma jet and is consisted of a solvent in which submicron ceramic particles are dispersed by using a dispersant. The latter allows adsorbing at the solid particles surface polymeric chains which exert electrostatic and steric repulsions between solid particles avoiding their agglomeration.

Submicron solid particles must be injected by the use of liquid carrier because of their low inertia and to bring them in the core of the plasma jet. A liquid jet (continuous or not) is used which diameter is about $300 \mu \mathrm{m}$ to inject suspensions. The plasma/liquid jet interaction first produces a primary fragmentation resulting in droplet size distribution within the plasma, liquid vaporization processes arise later, and solid particle are plasma sprayed to form a coating on a prepared substrate.

The fragmentation and vaporization processes completely govern the particle trajectories in the plasma plume further downstream from the nozzle exit [39]. That is why it is particularly important to control the liquid injection and its interaction with the plasma jet.

Fig. (20) depicts a time-resolved imaging of suspension injection within an $\mathrm{Ar}-\mathrm{H}_{2}(45-15 \mathrm{slm})$ plasma jet operating at 500 A. Fig. (20a, b) was obtained by using synchronized laser illumination (pulse duration $2 \mu \mathrm{s}$ ) and camera aperture (aperture time $10 \mu \mathrm{s}$ ) with a voltage level of 65 volts and 40 volts respectively. These voltage values correspond to different instantaneous electric powers and therefore different plasma enthalpies and velocities. The value 65 volts is also the mean arc voltage. Fig. (20a) shows that the liquid jet starts to be destabilized by natural fragmentation outside the plasma because droplets formation is observed. Then, inside the plasma jet, liquid jet is fragmented at necks of liquid jet instabilities. Further downstream droplets are fragmented, accelerated, heated and vaporized. Solid particles contained within these droplets also undergo acceleration, heating and melting. Fig. (20b) shows for the same operating conditions that fragmentation processes are different from Fig. (20a) because local momentum and enthalpy depends on plasma instabilities. This dispersion of fragmentation processes lead to produce large droplets size distributions with very different trajectories. Especially, solid particles contained in droplets travelling in the fringes of the plasma jet will be poorly plasma-treated and will cause defects in coatings as explained in the next section.

\subsection{Coatings Elaboration}

The main differences between Suspension Plasma Spraying (SPS) and Atmospheric Plasma Spraying (APS) are (see Table 2): 

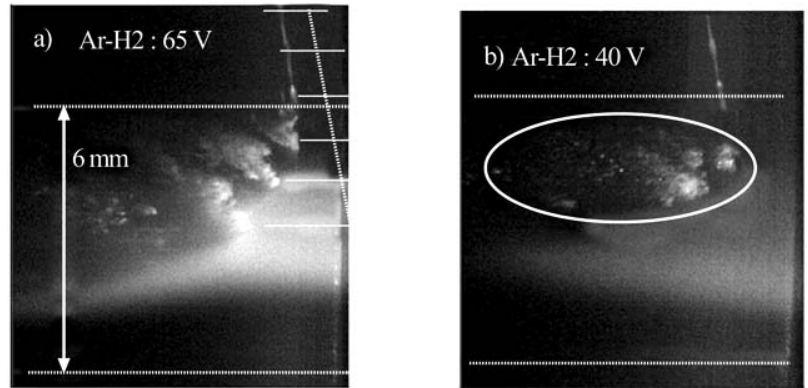

Fig. (20). Time-resolved imaging of suspension injection within an $\mathrm{Ar}-\mathrm{H}_{2}$ (45-15 slm) plasma jet operating at $500 \mathrm{~A}$; imaging is synchronized with the arc voltage of a) $65 \mathrm{~V}$ and b) $40 \mathrm{~V}$ [3].

1. the carrier gas used to provide micrometric-sized particles with adequate momentum to be injected into the plasma jet in APS that is replaced by a carrier liquid which experiences fragmentation (in a few $\mu$ s) and vaporization (in a few tens of $\mu s$ ) when interacting with the plasma jet;

2. the stand-off distance which is shorter in SPS $(\sim 30$ $40 \mathrm{~mm})$ compared to APS $(\sim 100-140 \mathrm{~mm})$ due to the lower thermal and kinetic inertia of submicrometric particles;

3. a higher heat flux transferred from the plasma to the substrate that can reach values as high as $35 \mathrm{MW} . \mathrm{m}^{-2}$ in some cases [40].

In SPS, the liquid stream or drops penetrate the plasma jet if their density of momentum $\left(\rho \times V^{2}\right.$ where $\rho$ is the liquid specific mass and $\mathrm{V}$ its velocity upon penetration) is made higher than the one of the plasma.

Upon penetration within the plasma flow, the liquid stream encounters two mechanisms, fragmentation and vaporization [41]. In a first approximation and whatever the droplet characteristic dimension, the vaporization duration is two orders of magnitude longer than the fragmentation one. Indeed, the fragmentation occurs for a liquid flow characteristic dimensionless Weber number, We, higher than 12-14 [42]. We represents the ratio of inertia forces to surface tension forces and is expressed as follows:

$W e=\frac{\rho_{\text {liquid }} \cdot \Delta V^{2} \cdot d_{\text {liquid }}}{\sigma_{\text {liquid }}}$

where $\rho_{\text {liquid }}$ is the liquid specific mass $\left[\mathrm{kg} \cdot \mathrm{m}^{-3}\right], \mathrm{d}_{\text {liquid }}$ the liquid stream characteristic dimension $[\mathrm{m}], \sigma_{\text {liquid }}$ the liquid surface tension (considered at ambient temperature in contact with air at ambient pressure) $\left[\mathrm{N} . \mathrm{m}^{-1}\right]$ and $\Delta \mathrm{V}$ the difference in velocities between the liquid stream and the plasma flow $\left[\mathrm{m} \cdot \mathrm{s}^{-1}\right]$.

The Weber number evolves along the penetration of the suspension within the plasma jet and can reach values as high as 350 leading to a catastrophic break-up [43].

One can envisage the following simplified scenario for the processing of a suspension made of micrometric-sized particles [44]:

1. fragmentation of the liquid stream occurred before solvent evaporates (two orders of magnitude);

2. solvent evaporation leads to the formation of single particles or aggregates constituted by a few grains;

3. these particles melt and form liquid drops which impact, spread and solidify to form flattened lamellae of equivalent diameters between a few hundred nanometers to a few micrometers.

Lamellae resulting from impact, spreading and solidification onto the substrate of impinging particles are characterized, apart their typical size, by:

1. almost the absence of peripheral projections around the lamellae; this signifies that the dimensionless flattening Sommerfeld number, $K_{\mathrm{f}}$, is lower than 6 [45];

2. the absence of intralamellar cracks within the lamellae, a contrario to lamellae collected under conventional plasma spray conditions, indicating that the residual quenching stress developing within the lamellae upon rapid solidification and cooling are lower than the intrinsic mechanical resistance of their constitutive material.

As shown in Fig. (21), the layer results from the stacking of such lamellae and exhibits hence a typical granular structure. Indeed, SPS layers are made of lamellae (molten particles, W), angular particles (unmolten particles, U) and small spherical grains (molten particles resolidified prior their impact upon the substrate, R).

This very typical architecture results from several effects / mechanisms:

1. SPS is particularly sensitive to the arc voltage fluctuations induced by the arc instabilities as shown in Fig. (20). Under such conditions, the available

Table 2. Major Differences Between APS and SPS Processes

\begin{tabular}{|l|c|c|}
\hline \multicolumn{1}{|c|}{ Characteristics } & APS & SPS \\
\hline \hline particle average size $[\mu \mathrm{m}]$ & $20-50$ & $0.02-1.0$ \\
\hline $\begin{array}{l}\text { particle relative mass }[-] \\
(\mu \mathrm{m} \text { or } \mathrm{nm}) / \mu \mathrm{m}\end{array}$ & 1 & $1.10^{-9}-1.10^{-3}$ \\
\hline feedstock carrier & gas (Ar usually) & liquid $\left(\mathrm{H}_{2} \mathrm{O}\right.$ or Et-OH) + additives \\
\hline particle mass flow rate $\left[\mathrm{g} \cdot \mathrm{min}^{-1}\right]$ & $20-50$ & $0.75-6$ \\
\hline stand-off distance $[\mathrm{mm}]$ & $100-140$ & $30-50$ \\
\hline heat flux at stand-off distance $\left[\mathrm{MW} \cdot \mathrm{m}^{-2}\right]$ & $2-0.5$ & $25-10$ \\
\hline
\end{tabular}


energy in the plasma flow is fluctuating together with the plasma velocity, so that the different steps in suspension processing (liquid fragmentation, solvent vaporization and solid particles melting and acceleration) are not achieved at the same rates all along the time of flight of the feedstock [46].

2. If the particle size distribution of the solid particles in the suspension is fairly large, this leads to very different characteristic times in the particles processing [46]. In this case, it has been shown that the resulting microstructure of the coating can be quite porous. Instead, when spraying solid particles with a narrow particles size distribution, opened porosities can be substantially reduced $[47,48]$.

3. In interaction with the plasma jet, the suspension jet crumbles. The first droplets, containing solid particles, fragment from the suspension jet and remain in the plasma fringe whereas the jet continues its trajectory towards the plasma core [49]. Although, the plasma jet is characterized by sharp thermal and kinetic radial gradients leading to an inhomogeneous treatment of particles along their trajectories. The solid particles that penetrated into the plasma core will impact upon the substrate in a molten state and form splats whereas those traveling in the plasma fringes of lower temperature, will remain untreated and form angular embedded particles. The spherical particles are very likely the smallest ones which penetrated deep into the plasma jet and for which thermophoresis and related effects become nonnegligible due to their size. Those particles could be hence ejected again in the fringes where they resolidified due their low thermal inertia.

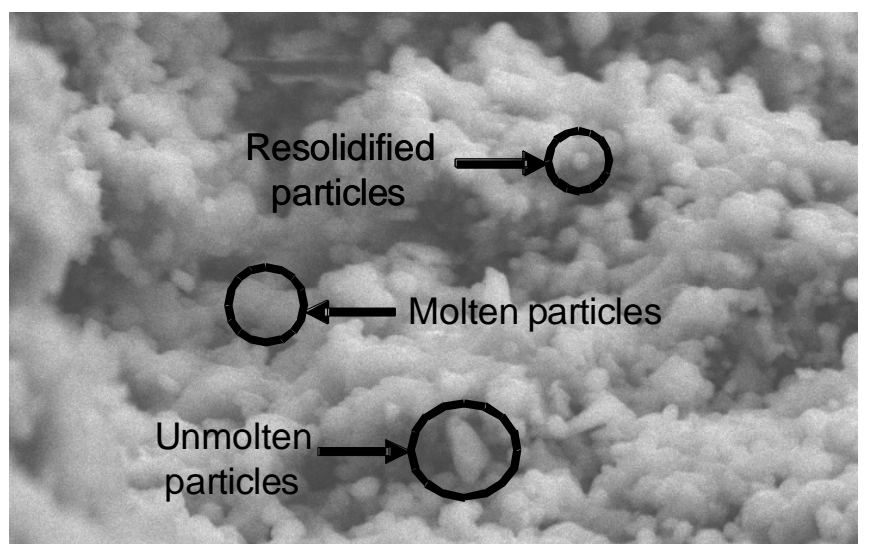

Fig. (21). Typical $\mathrm{Al}_{2} \mathrm{O}_{3}$ SPS layer architecture (feedstock $\mathrm{d}_{50}=500$ $\mathrm{nm}$, solvent: Et-OH, particle mass load in suspension MP $=20 \%$, mechanical suspension injection, Ar- $\mathrm{H}_{2}$ 45-15 SLPM plasma forming gases, plasma arc current intensity $\mathrm{I}=500 \mathrm{~A}$, torch internal nozzle diameter $\varnothing=5 \mathrm{~mm}$, plasma mass enthalpy $\mathrm{h}=14 \mathrm{MJ} \cdot \mathrm{kg}^{-1}$ ).

So, depending on their size and trajectories, the particles experience different thermal histories and trajectories leading to different molten state and impact location onto the substrate. Depending upon the fraction of poorly treated particles (processed or re-solidified in the plasma jet core fringes) to the one of appropriately treated (processed in the plasma core and in a molten state when impacting), the coating architecture will evolve from fairly dense (low fraction of poorly treated) to fairly porous (high fraction of poorly treated), as depicted in Fig. (22). Densifying the layer architecture requires hence reducing the fraction of poorly treated particles.

a)

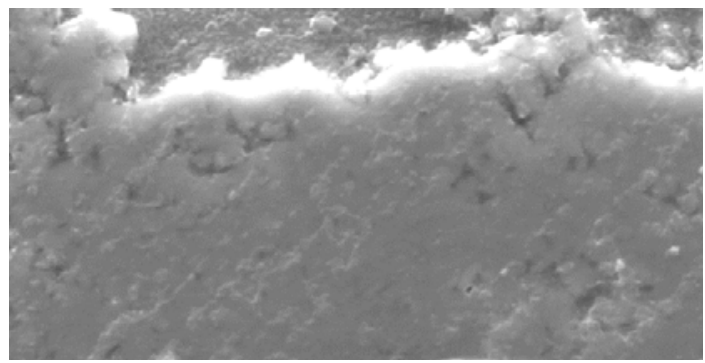

b)

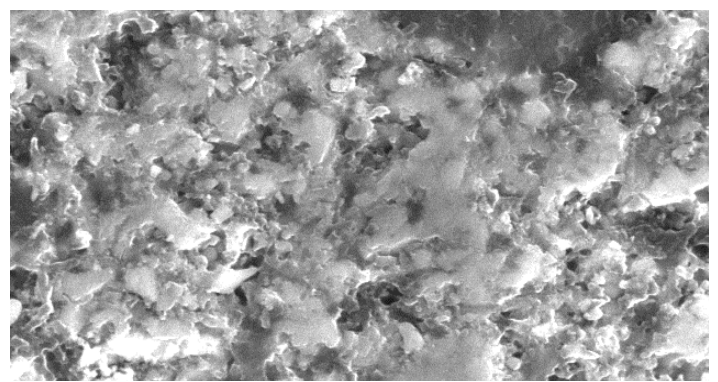

Fig. (22). Typical $\mathrm{Al}_{2} \mathrm{O}_{3}$ SPS layer architectures manufactured with a) a low fraction of poorly treated particles (spray distance: $30 \mathrm{~mm}$ ) and b) a high one (spray distance :50 mm) (feedstock $d_{50}=500 \mathrm{~nm}$, solvent: Et-OH, MP $=20 \%$, mechanical suspension injection, Ar$\mathrm{H}_{2}$ 45-15 SLPM, I = $500 \mathrm{~A}, \varnothing=5 \mathrm{~mm}, \mathrm{~h}=14 \mathrm{MJ} \cdot \mathrm{kg}^{-1}$ ).

Apart this mechanism, layer architecture depends also upon the manner successive spray patterns (or deposited beads) overlap [50]. The geometry of the spray pattern can be approximated by a Gaussian function that size and shape depend upon the deviation and dispersion of the particle stream at the spray distance (depending themselves upon the plasma power and feedstock injection parameters), the particle state upon impact and the relative substrate / plasma torch velocity. For fixed spray pattern size and shape, the overlapping depends upon the lateral plasma torch scanning step.

Pawlowski et al. [51] identified eight classes of stacking defects in plasma sprayed coatings. In the case of micrometer-sized ceramic coatings manufacturing by atmospheric plasma spraying (APS), the coating is characterized by:

1. its anisotropic lamellar structure;

2. its void (or globular pore content) which results from stacking defects between lamellae;

3. intralamellar cracks resulting from stress relaxation during lamella rapid solidification (i.e., average cooling rate of the order of $10^{6} \mathrm{~K} . \mathrm{s}^{-1}$ ) after spreading;

4. interlamellar delaminations due to poor contact between flattened lamellae. The combination of these features generates a complex 3-D interconnected network of pores [52].

Pore size distribution and their formation mechanisms of SPS coatings are not really well understood yet. One of the reasons comes from the scale size difference between APS and SPS feedstock powder used (in the order of $10^{8}$ when 
considering particle volume) and, very likely, from different manufacturing mechanisms. In fact, the typical anisotropic lamellar structure of APS coatings is not anymore duplicated at smaller size when considering SPS coatings. Indeed, the particle flattening rate (defined by the $\xi=D / d$ ratio where $D$ represents the lamella diameter and $d$ the initial diameter of the impinging particle, [53]) in SPS is much smaller compared to APS coatings.

Fig. (23) displays two typical features in a SPS coating architecture: a through-thickness granular one and a layered one that develops at the coating/substrate interface.

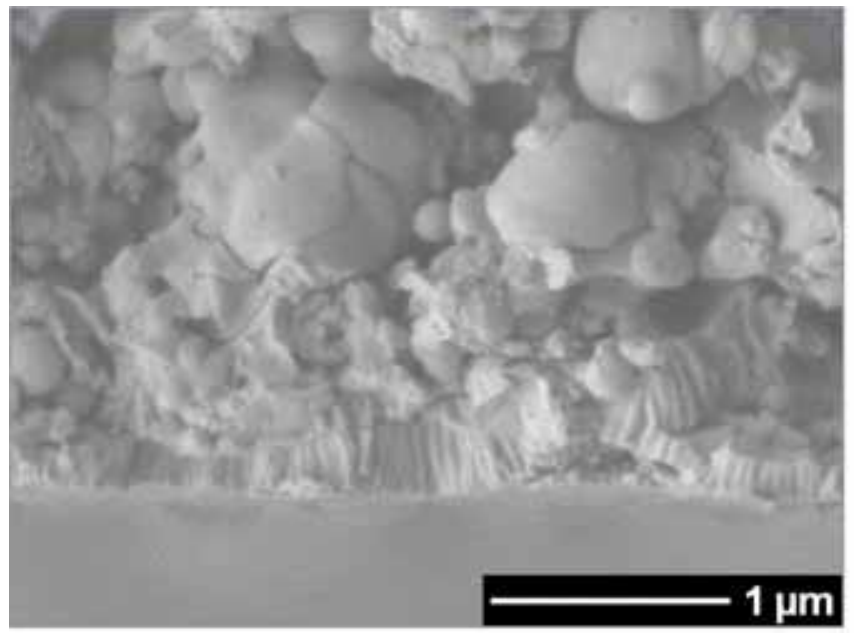

Fig. (23). Fractography facieses of a SPS coating (8YSZ, d50 of the particle size distribution: $50 \mathrm{~nm}$ ).

At the substrate/coating interface, a fairly dense lamellar layer of thickness thinner than $1 \mu \mathrm{m}$ develops. The thin layer is formed by the stacking of flattened particles exhibiting flattening ratios much higher than in the rest of the coating. Indeed, one can assume that once a thin layer of YSZ is formed, the thermal resistance would significantly increase, hence delaying the cooling of subsequent impinging particles. This would allow the flattened particles to remain in a molten state for longer times. Since particles are nanometer-sized, the surface tension at the end of the flattening stage plays a more important effect compared to the one on micrometer-sized flattened particles. Recoil of molten lamellae leads to the formation of spherical particles and ultimately the granular structure.

Besides, the density of stacking defects in the lamellar layer depends upon operating parameters. Fig. (24) depicts the influence of chemical composition of plasma forming gases of coatings manufactured with $\mathrm{Ar}-\mathrm{H}_{2}$ (Fig. 24a) and Ar-He (Fig. 24b). More stacking defects are visible in the lamellar layer processed with an $\mathrm{Ar}-\mathrm{H}_{2}$ plasma gas mixture. As explained in section 2.3, the chemical composition of plasma forming gases affects the electric arc properties and the dynamic and thermal transfers between the plasma and solid particles. Operating the plasma torch under an $\mathrm{Ar}-\mathrm{H}_{2}$ plasma gas mixture favors the restrike operating mode [53] characterized by large relative voltage variations (i.e., $\Delta \mathrm{V} /$ $\mathrm{V} \sim 1.0$ ) and leads to a less homogeneous processing of suspensions compared to an Ar-He plasma gas mixture that favors a more stable operating mode called takeover mode (i.e., $\Delta \mathrm{V} / \mathrm{V} \sim 0.3)[30]$.
Moreover, the pressure model of section 2 is helpful to highlight other particular properties of helium with respect to hydrogen. Fig. (25) shows the pressure variations defined in section 2 (section Fig. 7) as function of the product $\dot{m}^{2} h_{0}$ for Ar-He and Ar-He- $\mathrm{H}_{2}$ mixtures. At fixed $\dot{m}^{2} h_{0}$, it is observed that pressure variation is higher when using an $\mathrm{Ar}-\mathrm{H}_{2}$ binary mixture than with a $\mathrm{Ar}-\mathrm{H}_{2}-\mathrm{He}$ ternary mixture.

When adding a slight amount of hydrogen $\mathrm{H}_{2}$ within an Ar-He mixture, this pressure variation decreases. The mean isentropic coefficient is therefore smaller for an Ar-He- $\mathrm{H}_{2}$ than for an Ar-He mixture. This observation implies that, at fixed parameter $\dot{m}^{2} h_{0}$, the addition of hydrogen $\mathrm{H}_{2}$ contributes to decrease the plasma jet velocity. This is because part of thermal energy is converted into dissociation energy due the presence of hydrogen molecules instead of being used as mechanical energy.

That is why Ar-He mixtures not only limit the arc instabilities but also favors momentum transfers due to higher plasma jet velocities and the well-known high dynamic viscosity of helium as well. The treatment of solid particles is therefore more homogeneous with $\mathrm{Ar}-\mathrm{He}$ mixtures than with $\mathrm{Ar}-\mathrm{H}_{2}$ ones.

a)

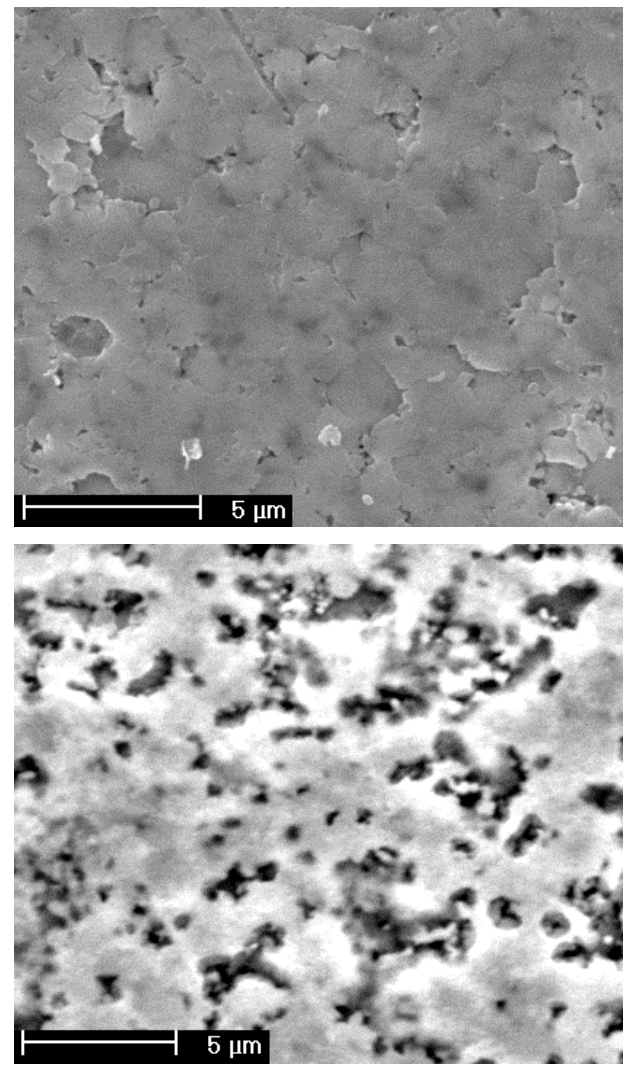

Fig. (24). Comparison of substrate/coating interfaces as function of plasma gas composition. a) $\mathrm{Ar}-\mathrm{He}$ gas mixture. b) $\mathrm{Ar}-\mathrm{H}_{2}$ gas mixture. (SE-SEM pictures).

Gas adsorption analyzes reveal an open connected porosity rate from $1.9 \%$ to $4.1 \%$ depending upon the operating parameters used. Contrary to APS micrometer-sized coatings, most of the pores in SPS coatings are closed. The decrease in spray distance leads to a decrease of the total pore content without significant variations of the open / total pore content, 
contrary to the selected plasma gas mixture. These results prove that plasma gas mixtures and the resulting operating mode are very important parameters to take in consideration to tailor SPS coating architecture. In the case of thermal barrier coatings for example, using an $\mathrm{Ar}-\mathrm{H}_{2}$ plasma gas mixture would permit to increase the total pore content contrary to an Ar-He one that will induce a denser coating with a lower permeability, more suitable to manufacture SOFC electrolytes.

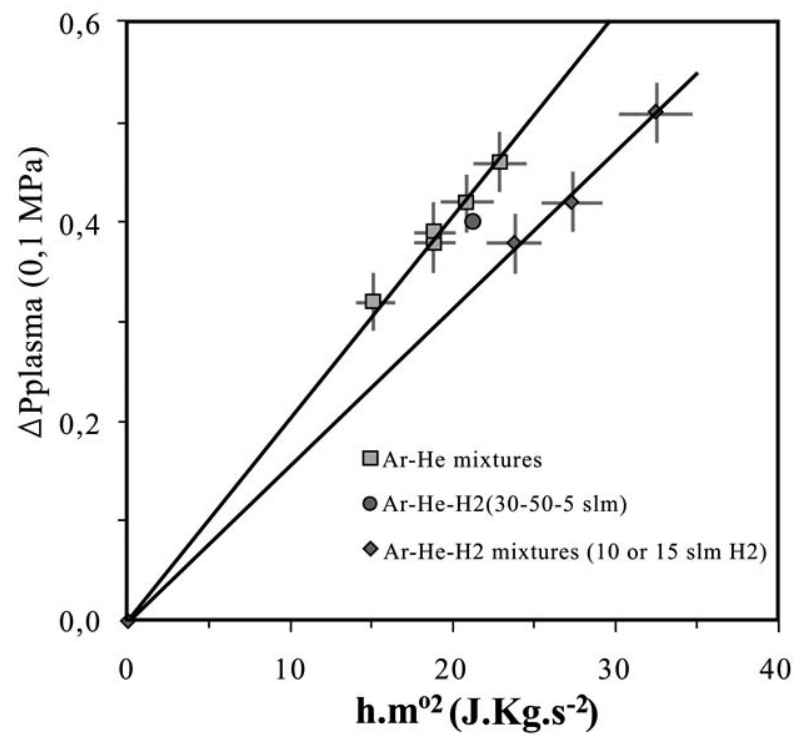

Fig. (25). Pressure variation $\Delta P_{p}=P_{z}-\left(P_{a}+\Delta P_{f}\right)$ as function of the product $\dot{m}^{2} h_{0}$ where $\mathrm{P}_{\mathrm{t}}, \mathrm{P}_{\mathrm{a}}$ and $\Delta P_{f}$ are respectively the total pressure, the atmospheric pressure and the losspressure due to the plasma gases for $\mathrm{Ar}-\mathrm{He}$ and $\mathrm{Ar}-\mathrm{He}-\mathrm{H}_{2}$ and internal nozzle diameters of $6 \mathrm{~mm}$.

\section{CONCLUSION AND PERSPECTIVES}

Since about a decade, the interest to manufacture on large surfaces "thick" finely structured or nano-structured layers has been increasingly growing. If nano-structured architectures can be manufactured by gas condensation routes (CVD, PE-CVD, PVD, EB-PVD, etc.), their thicknesses can hardly be higher than a few micrometers. On the contrary, plasma spray coating thicknesses between 50 to a few millimeters are easily achieved but with no nano-structured architectures after particle melting. This explains the interest for suspension plasma spraying (SPS) allowing achieving finely structured layers (ceramic/metallic) of thicknesses varying between a few micrometers up to a few hundred of micrometers. As the deposition rate can reach one fifth to one fourth of the one encountered in conventional plasma spraying, this technique seems promising to manufacture dense or porosity controlled coatings and functionally graded layers. Nevertheless, compared to conventional plasma spraying, SPS is by far more complex because of fragmentation and vaporization processes of the liquid and of the necessity to plasma-treat solid particles with submicron diameters. Numerous studies are still necessary to reach a better understanding of involved phenomena and for that, the development of diagnostic techniques to quantify either the droplets or particles in flight temperature and velocity or to visualize the droplets / plasma interactions must be improved or newly developed.
These new processes are obviously depending on the plasma source which must present the advantage to involve high levels of specific enthalpy in the plasma jet to vaporize the liquid and to treat refractory materials. Blown arc plasma source is appropriate but efforts must be carried out to have a better understanding of the influence of operating parameters on plasma jet properties and to improve plasma stability. Otherwise, SPS process could be limited in its development and therefore in its application field.

This paper has presented two complementary approaches aiming at, first, predicting the plasma jet properties as function of very simple averaged measurements, and, second, focusing on the origin of electric arc instabilities of blown arc sources.

The first approach must satisfy immediate needs to on-line control the SPS process by very reliable averaged measurements. It is indeed well known for example that the mean voltage of dc plasma torch decreases with time due the erosion of electrodes. This voltage reduction causes a slow drift of processes which leads to change plasma jet properties and therefore dynamic and thermal transfers between plasma and solid particles. The resulting coating properties also change all the more than solid particles are small due to their low inertia. As shown in the model of section 2, in case of significant electrode erosion, the plasma specific enthalpy available decreases and plasma velocity as well. As also suggested in section 2, pressure measurement on the gas feeding line is a very good candidate for monitoring SPS process because it connects specific enthalpy and velocity.

The second approach is also important because the characteristic times of electric arc instabilities are higher than those of dynamic and thermal transfers of submicron particles found in SPS. Unstable plasma sources degrade coatings properties by incorporating poorly plasma treated solid particles.

Electric arc instabilities have to be reduced to obtain a homogeneous plasma treatment of injected precursors. Particularly, investigations about the origin of arc instabilities should be carried out regarding the influence of the coupling between fluid instabilities generated by the plasma torch and the electric arc. At last, results about the rearcing phenomena through the boundary layer at anode are still missing because of the difficulty to experience measurements in such a region. Even though, during these last years, many studies will be devoted to obtain realistic modeling of blown arc plasma sources, the magneto-hydrodynamic description of a three dimensional and transient plasma (out of local thermodynamic equilibrium), which involves different scales of space and time, still requires many efforts to account for the effects previously evoked.

\section{REFERENCES}

[1] Heberlein J. New approaches in thermal plasma technology. Pure Appl Chem 2002; 74: 327-35.

[2] Fauchais P, Etchart-Salas R, Delbos C, et al. Suspension and solution plasma spraying of finely structured layers: potential application to SOFCs. J Phys D Appl Phys 2007; 40: 2394-406.

[3] Fauchais P, Etchart-Salas R, Rat V, Coudert JF, Caron N, WittmannTénèze K. Parameters controlling liquid plasma spraying: Solutions, sols, or suspensions. J Therm Spray Technol 2008; 17: 31-59.

[4] Fauchais P, Vardelle A. Thermal Plasmas. IEEE Trans Plasma Sci 1997; 25 : $1258-80$.

[5] Schein J, Zierhut J, Dzulko M, Forster G, Landes KD. Improved Plasma Spray Torch Stability Through Multi-Electrode Design. Cont Plasma Phys 2007; 47: 498-504. 
[6] Tahara H, Ando Y. Study of titanium nitride deposition by supersonic plasma spraying. Vacuum 2008; 83: 98-101.

[7] Heberlein J, Murphy AB. Thermal Plasma waste treatment. J Phys D Appl Phys 2008; 41: 053001.

[8] Park JM, Kim KS, Hwang TH, Hong SH. Three-dimensional modeling of arc root rotation by external magnetic field in nontransferred thermal plasma torches. IEEE Trans Plasma Sci 2004; 32: 479-87.

[9] Kim KS, Park JM, Choi S, Kim J, Hong SH. Enthalpy probe measurements and three-dimensional modelling on air plasma jets generated by a non-transferred plasma torch with hollow electrodes. J Phys D Appl Phys 2008; 41: 065201.

[10] Freton P, Gonzales JJ, Gleizes A, Escallier G, Van Ootegem B. Arc movements in a hollow cathode of high-power plasma torch. IEEE Trans Plasma Sci 2008; 32: 1044-5.

[11] Oost GV, Hrabovsky M, Kopecky V, Konrad M, Hlina M, Kavka T. Pyrolysis/gasification of biomass for synthetic fuel production using a hybrid gas-water stabilized plasma torch. Vacuum 2009; 83: 209-12.

[12] Pfender E. Thermal plasma technology: Where do we stand and where are we going? Plasma Chem Plasma Process 1999; 19: 1-31.

[13] Fauchais P, Vardelle A. Pending problems in thermal plasma and actual development. Plasma Phys Control Fusion 2002; 42: B365-B83.

[14] Fauchais P, Vardelle A, Dussoubs B. Quo vadis thermal spraying. J Therm Spray Technol 2001; 10: 44-66.

[15] Gleizes A, Gonzalez JJ, Freton P. Thermal plasma modeling. J Phys D Appl Phys 2005; 38: R153-83.

[16] Rat V, Murphy AB, Aubreton J, Elchinger MF, Fauchais P. Treatment of non-equilibrium phenomena in thermal plasma flow. J Phys D Appl Phys 2008; 41: 183001

[17] Murphy AB, Boulos MI, Colombo V, et al. Advanced thermal plasma modeling. High Temp Mater Process 2008; 12: 255-336.

[18] Trelles JP, Chazelas C, Vardelle A, Heberlein JVR. Arc Plasma Torch Modeling. J Thermal Spray Technol; in press.

[19] Coudert JF, Delalondre C, Roumilhac P, Simonin O, Fauchais P. Modeling and experimental study of a transferred arc stabilized with argon and flowing in a controlled-atmosphere chamber filled with argon at atmospheric pressure. Plasma Chem Plasma Process 1993; 13: 399432.

[20] Meacker H. Plasmaströmungen in Lichtbögen infolge eigenmagnetisher kompression. Z Phys 1955; 141: 198-216.

[21] Boulos MI, Fauchais P, Pfender E. Thermal Plasmas: Fundamentals and Application 1; New York, ( Plenum) 1994.

[22] Jacob M. Heat Transfer. New York: John Wiley \& Sons 1962; vol. 1: p. 192.

[23] Rat V, Coudert JF. A simplified analytical model for dc plasma spray torch: influence of gas properties and experimental conditions. J Phys D Appl Phys 2006; 39: 4799-807.

[24] Coudert JF, Planche MP, Fauchais P. Characterization of D.C. plasma torch voltage fluctuations. Plasma Chem Plasma Process 1996; 16: 211S-27S.

[25] Burm KTAL, Goedheer WJ, Schram DC. The isentropic exponent in plasmas. Phys Plasmas 1999; 6: 2622-7.

[26] Gauvin WH. Some characteristics of transferred-arcs plasmas. Plasma Chem Plasma Process1989; 9: 65S-84S.

[27] Coudert JF, Planche MP, Fauchais P. Velocity measurement of dc plasma jets based on arc root fluctuations. Plasma Chem Plasma Process 1995; 15: 47-70.

[28] Crowe C, Sommerfeld M, Tsuji Y. Multiphase flows with droplets and particles. USA: CRC Press 1998.

[29] Meillot E, Balmigere G. Plasma spraying modeling: Particle injection in a time-fluctuating plasma jet. Surf Coat Technol 2008; 202: 4465-9.

[30] Wutzke SA, Pfender E, Eckert ERG. Study of electric-arc behaviour with superimposed flow. AIAA J 1967; 5: 707-14.

[31] Yang G, Heberlein JRV. The anode region of high intensity arcs with cold cross flow. J Phys D Appl Phys 2007; 40: 5649-62.

[32] Trelles JP, Pfender E, Heberlein JRV. Modelling of the arc reattachment process in plasma torches. J Phys D Appl Phys 2007; 40: $5635-48$
[33] Trelles JP, Pfender E, Herberlein JRV. Multiscale Finite Element Modeling dynamiocs in dc plasma torch. Plasma Chem Plasma Process 2006; 26: 557-75

[34] Coudert JF, Rat V, Rigot D. Influence of Helmholtz oscillations on arc voltage fluctuations in a dc plasma spraying torch. J Phys D Appl Phys 2007; 40: 7357-66.

[35] Coudert JF, Rat V. Influence of configuration and operating conditions on the electric arc instabilities of a plasma spray torch: Role of acoustic resonance. J Phys D Appl Phys 2008; 41: 205208.

[36] Blackstock DT. Fundamental of Physical Acoustics 2000 Wiley interscience. New York: John Wiley \& Sons Inc. 2000

[37] Siegert R, Döring JE, Marqués JL, Vaßen R, Sebold D, Stöver D. Denser ceramic coatings obtained by the optimization of the suspension plasma spraying technique. "Thermal Spray Solutions - Advances in Technology and Application", Pub. DVS-Verlag GmbH, 40223 Düsseldorf, Germany, 2005; ISBN: 3-87155-792-7.

[38] Bouaricha S, Oberste-Berghaus J, Legoux JG, Moreau CT. Chraska. Suspension plasma spraying of nano-ceramics using an axial injection torch. "Thermal Spray Connects: Explore its Surfacing Potential!". Lugscheider E, Ed. Pub. DVS-Verlag GmbH, 40223 Düsseldorf, Germany, 2005; ISBN 3-87155-793-5.

[39] Etchart-Salas R, Rat V, Coudert JF, Fauchais P, Lafougère G. Influence of arc instabilities on the injection in suspension plasma spraying. J High Temp Mater Process 2006; 10: 407-418.

[40] Etchart-Salas R. (in French). Atmospheric plasma spraying of submicron-sized solid particles in suspension. Experimental and analytical approach of involved phenomena in reproducibility and quality of coatings, Ph.D. thesis, University of Limoges, France, 2007.

[41] Gelfand BE. Droplet breakup phenomena in flows with velocity lag. Prog Energy Combust Sci 1996; 22(3): 201-65.

[42] Watanabe T, Ebihara K. Numerical simulation of coalescence and breakup of rising droplets. Comput Fluids 2003; 32: 823 -834.

[43] Lee CS, Reitz RD. Effect of liquid properties on the breakup mechanism of high speed liquid drops. Atomization Sprays 2001; 11: 119.

[44] Fazilleau J, Delbos C, Rat V, Coudert JF, Fauchais P, Pateyron B. Phenomena involved in suspension plasma spraying part 1: suspension injection and behavior. Plasma Chem Plasma Proc 2006; 26: 371-91.

[45] Fauchais P, Fukumoto M, Vardelle A, Vardelle M. Knowledge concerning splat formation : An invited review. J Therm Spray Technol 2004; 13: 337-60.

[46] Delbos C (in French). Contribution to the understanding of ceramic (YPSZ, perovskite, etc.) or metallic ( $\mathrm{Ni}$, etc.) particles injection by a liquid carrier in a plasma jet to manufacture finely-structured coatings for SOFC. Ph.D. thesis, University of Limoges 2004.

[47] Delbos C, Fazilleau J, Rat V, Coudert JF, Fauchais P, Pateyron B. Phenomena involved in suspension plasma spraying Part 2: Zirconia particle treatment and coating formation. Plasma Chem Plasma Process 2006, 26: 393-414.

[48] Fauchais P, Rat V, Delbos C, Coudert JF, Chartier T, Bianchi L. Understanding of d.c. suspension plasma spraying of finely structured coatings for SOFC. IEEE Trans Plasma Sci 2005; 33: 920-930.

[49] Tingaud O, Grimaud A, Denoirjean A, et al. Effects of operating parameters on SPS alumina coatings structures to manufacture functionally-graded layers. Surf Coat Technol; in press.

[50] Trifa FI, Montavon G, Coddet C. Model-based expert system for design and simulation of APS coatings. J Therm Spray Technol 2007; 16: 128139.

[51] Pawlowski L, Fauchais P. Thermal Transport Properties of Thermally Sprayed Coatings. Int Mater Rev 1992; 37: 271-289.

[52] Antou G, Montavon G, Hlawka F, Cornet A, Coddet C, Machi F. Evaluation of Modifications Induced on Pore Network and Structure of Partially Stabilized Zirconia Manufactured by Hybrid Plasma Spray Process. Surf Coat Technol 2004; 180-181: 627-632.

[53] Bianchi L. D.C. and R.F. Plasma Spraying of Ceramic Coatings: Mechanism of the Formation of the First Layer and its Link with Coatings Properties, Ph.D. thesis, University of Limoges, France 1995; (in French).

This is an open access article licensed under the terms of the Creative Commons Attribution Non-Commercial License (http://creativecommons.org/licenses/by$\mathrm{nc} / 3.0 /$ ) which permits unrestricted, non-commercial use, distribution and reproduction in any medium, provided the work is properly cited. 